\title{
DESIGN AND DEVELOPMENT OF AN ONLINE EXAM MAKER AND CHECKER
}

\author{
Maria Cristina M. Ramos, Janice E. Velasquez \\ Instructor, College of Computer Studies, \\ Lyceum of the Philippines University, Batangas City, Philippines \\ cm_ramos2003@yahoo.com \\ Instructor, College of Computer Studies, \\ Lyceum of the Philippines University, Batangas City, Philippines \\ ecinaj03@gmail.com
}

\begin{abstract}
The study is an online, computer aided tool that was designed primarily for the conduct of online examination. The system was created using PHP, a web based scripting language, and MySQL as the database software. The system focuses on the automation of students' examinations; preparation, scheduling, checking and grading. A database is provided for the storage of exam questions, answers to questions and students' records. The system allows instructors to create an exam by entering questions with its corresponding answers into the database. Instructors are provided with three options on the type of exam; these include, True or False, Multiple Choice and Fill in the Blanks.

There are three account types based on the intended users. One is the Administrator Account; this can be used to create instructor accounts. It can also be used to delete or suspend other accounts based on activity status. The Instructor Account allows teachers to create student accounts and enroll the same. This account can be used also to create, activate, edit, delete exams and monitor students' performances. The Student Account is for the officially enrolled students where they can take exams and view scores even from previous examinations.

This software allows instructors to keep track of students' performances from all exams since the results will be stored in a database linked to an online system. While taking the online exam, students can choose the number of exam questions that will be displayed on the screen at a given time.

A student can take the exam only on the specified date and time set by the instructor. Ideally, a particular exam should be taken only once. In cases of retakes due to valid reasons and special exam considerations, the instructor is given the option to administer the previously activated exam, edit or create a new set of questions.

One limitation though, this online system is not to be used to compute for the class performance for the final grade since this requires other components such as seat works, graded recitations, laboratory activities, etc. This only computes and shows the scores from previous exams and the average.
\end{abstract}

\section{Indexing terms/Keywords}

Online exam maker, online exam checker, online exam maker design, online exam maker development

\section{Council for Innovative Research}

Peer Review Research Publishing System

\section{Journal: INTERNATIONAL JOURNAL OF COMPUTERS \& TECHNOLOGY}

Vol 10, No 5 


\section{INTRODUCTION}

The Internet is a worldwide, publicly accessible, infrastructure of networks of different interconnected computers that transmit data by packet switching using the standard Internet Protocol commonly referred to as IP. It consists of millions of networks which carry various information and services such as electronic mail, file transfer, advertisements and educational tools. Through the linkage of large computers that manage individual networks, the Internet becomes an information highway that makes the information stored on thousands of computers worldwide available to millions of people everywhere.

Recently, the Internet became quite popular in the field of education. Because of the vast range of information it offers, the Internet became an online library that caters to worldwide users mostly students in various fields. It made learning and information gathering easier for the students as well as other people from the academe.

Since then, the Internet evolved from just being an online library into other services such as online tutorial services and web-based trainings. Such trainings made life easier for students, since physical presence within the school is no longer a requirement to learn from lectures and take up assessments or exams. Students can enroll and attend lectures from academic institutions even in abroad without leaving their houses or countries which can eventually reduce the time and cost in learning from such institutions.

Similar to the traditional method of learning, web-based trainings and online services require assessments or examinations to pass curriculums. Assessment is a very important tool to determine the amount of learning a student has acquired. It is also a determinant if a student is already qualified for the next level of training. Thus, it is a must for examination questions to be carefully prepared. The construction of questions as well as accuracy in the checking of answers should be accomplished properly. The instructor needs to determine the type of exam and the topics to be included.

Instructors from the College of Computer Studies consider that test preparation, correction, and evaluation make up a significant portion of their time. Instructors being conscientious are further concerned about the quality of questions asked and methods for improvement in the evaluation of students' learning. Instructors often find themselves reusing questions or the whole exams, with the main concern of students' accidentally or purposefully finding out questions before the exam date. In this light, test creation becomes daunting, especially when the exam is to be administered to hundreds of students.

Online assessment can be a useful tool for teachers preparing exams and also the checking of exams. Randomization of questions is done in order to lessen cheating among students.

Cheating is a serious problem being encountered by teachers using the traditional method of giving examinations. Since exams are all the same in format and content, students can easily create tactics or strategies on how to cheat. This problem can be greatly reduced by online or computer aided assessment.

Online assessments will help reduce paper-based exams. Since it is automated, the instructor will just choose from different templates to create different types of exam. It is secured and the format of exam will be different for each student. Most importantly, online assessments have built-in databases where the student records can be stored for future viewings.

The study is entitled as "Design and Development of an Online Exam Maker and Checker for Lyceum of the Philippines University-Batangas" since it is actually an alternative method in which instructors can create an exam and automatically generate exam results of students. This can be done thru the facilities of the Internet or what is known as the "online method".

\section{OBJECTIVES OF THE STUDY}

Specifically, this study has the following objectives:

1. To develop a software that can serve as an alternative tool for students in taking examinations.

2. To provide the instructors with a useful tool in the preparation and checking of examinations as well as the maintenance of an online class record.

3. To provide a tool equipped with security measures that can be used to minimize cheating among students.

4. To provide a tool that can be used to administer exams online rather than using traditional paper-based exams.

\section{LITERATURE REVIEW}

A Computer-Based Assessment (CBA), also known as Computer-Based Testing (CBT), e-exam, computerized testing and computer-administered testing, is a method of administering tests in which the responses are electronically recorded, assessed, or both. As the name implies, Computer-Based Assessment makes use of a computer or an equivalent electronic device (i.e. handheld computer). CBA systems enable educators and trainers to author, schedule, deliver, and report on surveys, quizzes, tests and exams. Computer-Based Assessment may be a stand-alone system or a part of a virtual learning environment, possibly accessed via the World Wide Web. (http://en.wikipedia.org/wiki/Computer-based_testing) 
General advantages of Computer-Based Assessment (CBA) systems over traditional Pen-and-Paper Testing (PPT) have been demonstrated in several comparative works and includes: increased delivery, administration and scoring efficiency; reduced costs for many elements of the testing lifecycle; improved test security resulting from electronic transmission and encryption; consistency and reliability; faster and more controlled test revision process with shorter response time; faster decision-making as the result of immediate scoring and reporting; unbiased test administration and scoring; fewer response entry and recognition errors; fewer comprehension errors caused by the testing process; improved translation and localization with universal availability of content; new advanced and flexible item types; increased candidate acceptance and satisfaction; evolutionary step toward future testing methodologies. In addition to traditional testing approaches carried out in a paper-pencil mode, there are a variety of aspects needed to be taken into account when computer-based assessment (CBA) is deployed, such as software quality, secure delivery, reliable network (if Internetbased), capacities, support, maintenance, software costs for development and test delivery, including licenses. Any of the delivery modes, whether Paper-Pencil and/or computer-based, comprises advantages and challenges which can hardly be compared, especially in relation to estimated costs. The use of CBA includes additional benefits which can be achieved from an organizational, psychological, analytical and pedagogical perspective. Many experts agree on the overall added value and advantages of e-testing in large scale assessments. (http://en.wikipedia.org/wiki/Computer-based_testing)

The increasing use of computers in schools and classrooms has prompted educators, testing experts and test developers to look at ways of applying technology to student assessment. Many supporters argue that computerized exams are more in line with current instructional practices and the way students are accustomed to learning. Interest also has been piqued as greater emphasis is placed on assessments. While pencil-and-paper tests remain the standard form of test taking, the hope is that technology can provide a more efficient and possibly more effective way to administer student exams. While computer-assisted testing at some schools has been around for several years, broad-scale use is still in its beginning stages. Testing companies have used computers to administer professional exams and, increasingly, graduatelevel exams are being taken via computers. (http://www.ecs.org/html/issue.asp?issueid=12\&subissuelD=76)

Computer-Based testing (CBT), sometimes referred to as Computer-Assisted Examination, is perhaps the simplest application of computing technology to the evaluation process. Basically it consists of the transfer of conventional testing instruments such as multiple-choice examinations to the computer. Students refer to questions on a monitor and highlight their choices using a mouse or cursor, or by typing a letter or number. When programmed correctly, such CBT allows students to review responses, go back to change answers, and quit the exam when finished. .Additional formats such as matching questions, completion tasks, and even essay questions may be programmed for computers or individual work stations on local area networks (LAN). Computer-based testing is becoming the primary test administration mode for an increasing number of large-scale licensure and certification programs. The primary drive behind this change is the test administration efficiencies that can be achieved, such as flexible scheduling and fast scoring. Looming on the horizon, however, are revolutionary changes in test and item design that will be driven by computer-based changes in formal and informal learning environments. The learning/assessment force that was to be awakened by harnessing computer technology and learning technology ("programmed learning" and "computer-assisted instruction") during the educational reforms in the 1960s and 1970s never materialized. The technology could not keep up with the dream. The giant stirred but slept again. But now, more than thirty years later, a solid technological infrastructure is being put in place which will enable a partnership of learning and assessment that will more than exceed the dreams of those early pioneers. While there are many challenges ahead in realizing the full potential of computer technology, including the Internet, for enhancing learning and assessment, the fundamental challenge of creating the infrastructure has been met. The giant is waking up. Computer-based testing has come of age because computer-based learning has come of age. There is no choice but to re-design tests and testing programs to keep pace. (http://www.clearhq.org/Slaughter.htm)

The study entitled "Expert System in Choosing a CAS Course in Batangas City" by Baleros, Jerwin, et al. al., is a system that provides a means for enhancing the probability in choosing the right course based on numerous options in the different schools in Batangas City. It aids in decision-making by providing a series of tests. The tests therefore, will be graded based on the capacity of the examiner; thus generating the appropriate course.

The study entitled "Electronic Class Record and Computerized Grading System in Lyceum of Batangas" by Cordero, Ronald, et al. al., focuses on the accuracy, speed in computation and real-time access to student grades. It enables instructors to compute students' outputs based on performances for the whole semester.

The study entitled "Automated Entrance Examination Result of Lyceum of Batangas" by Escalona, Judy, et al., eliminates the use of paper and pencil type of testing in Lyceum of Batangas. It focuses on database design that is capable of storing and retrieving exam results, checking and interpreting school ability indexes (SAls), percentile ranks and standing done automatically. It is also a network-based type which requires registration for students to take the exam. Test questions are randomized so as to minimize cheating and the database is password protected for security purposes.

The study entitled "Internet-Based Exam Generator System for Review of the Fundamental of Engineering Exam" by JiHoon Lee is a system that generates randomized questions on different engineering topics. The system using a set of problem templates that when activated generates different variables for the same questions. The generator program changes the problems' variables and the order of computation. Graphics for the problem are also generated. The program uses PERL, JavaScript, CGI, Flash, HTML, SQL, databases and graphic programs. (http://eml.ou.edu/paper/hoime.htm)

The study entitled "Online Evaluation in WWW-based courseware: The QUIZIT System" by Lucio Kunha Tinoco has been developed to support adaptive and standard testing, along with automatic grading, record keeping and test administration using the World Wide Web as a delivery vehicle. The authors have applied QUIZIT in connection with their NSF supported Education Infrastructure Project on Interactive Learning with a Digital Library in Computer Science to help with evaluation 
in a master's level course as well as large freshmen level service course. (http://scholar.lib.vt.edu/theses/available/etd$638192839711171)$

The website http://testmaker.com/sells exam software. This site has a downloadable demo that expires within 1 to 5 minutes. It has a variety of links that show software functions. It also includes screen shots of the software layout. The software being offered by this web site has the capability of creating different exam types that can be hard copied or taken online.

The website http://prometric.com offers an array of services to its clients. From distance learning assessments to large scale assessments such as TOEFL, iBT, it offers solutions tailored to programs and business needs such as:

- Assessments designed for both traditional and non-traditional academic clients.

- Fixed administration and flexible scheduling in a secure testing environment for high stakes exams.

- Multiple item types to enhance real world scenarios, certification programs and international expansion.

- ezSeat, seat blocking for large groups on a pre-arranged basis.

Founded in 1999, ExamsOnline.com is one of the global leaders and the pioneer in providing many critical IT certification and assessment services online. Examsonline.com has been providing online IT certification such as Exam Prep , Preand Post-Assessment, CertAdvisor, CertBooks and many other IT certification related services to professionals and organizations worldwide. ExamsOnline.com certification exam preparation tools prepares the candidate to pass certification exams for all major vendors such as Microsoft, CompTIA, Oracle, Cisco, Novell, Sun, PMI. Candidates and organizations can also use Examsonline.com creative pre \& post assessment tools to test their skills.

The proposed software has almost the same features and functions in terms of exam creation for knowledge assessment, online connectivity and the randomization of questions. It is Web-based and it can be installed on almost any server. For users (test-takers), Online Exam Maker and Checker requires a computer or PDA with a Web browser (i.e. Mozilla Firefox or Internet Explorer) and an Internet or Intranet connection. Online Exam Maker and Checker automates all assessment phases: authoring, scheduling, delivering, and reporting. It's easy to use and do not require expensive hardware to run, nor additional commercial software.

The general advantages of Online Exam Maker and Checker over traditional Pen-and-Paper Testing (PPT) includes: increased delivery, administration and efficiency; reduced costs for many elements of the testing lifecycle; improved test security resulting from electronic transmission and encryption; consistency and reliability; faster and more controlled test revision process with shorter response time; faster decision-making as the result of immediate scoring and reporting unbiased test administration and scoring; fewer response entry and recognition errors; fewer comprehension errors caused by the testing process; improved translation and localization with universal availability of content.

The following studies "Expert System in Choosing a CAS Course in Batangas City", "Electronic Class Record and Computerized Grading System in Lyceum of Batangas" and "Automated Entrance Examination Result of Lyceum of Batangas" are stand alone systems each focusing on a respective topic. "Internet-Based Exam Generator System for Review of the Fundamental of Engineering Exam" and "Online Evaluation in WWW-based courseware: The QUIZIT System" differs from Online Exam Maker and Checker in the sense that questions are already built in to the system, additional questions cannot be installed. To be able to use testmaker.com and prometric.com, a certain fee is required, wherein Online Exam Maker and Checker will be linked to Lyceum of the Philippines IVLE and instructors and students will be able to use it. Online Exam Maker and Checker software will differ also in terms of layout and some capabilities like database storage and sorting of users in form of classes.

The journal entitled "Computer Based Assessment Systems Evaluation via the ISO9126 Quality Model" by Salvatore Valenti, Alessandro Cucchiarelli, and Maurizio Panti stated that "The interest in developing Computer Based Assessment (CBA) systems has increased in recent years, thanks to the potential market of their application.

Many commercial products, as well as freeware and shareware tools, are the result of studies and research in this field made by companies and public institutions. This noteworthy growth in the market raises the problem of identifying a set of criteria that may be useful to an educational team wishing to select the most appropriate tool for their assessment needs. The scientific literature is very poor in respect of this issue. An important help is provided in this direction, by a number of research studies in the field of Software Engineering providing general criteria that may be used to evaluate software systems. Furthermore, a relevant effort has been made in this field by the International Standard Organization that in 1991 defined the ISO9126 standard for "Information Technology - Software Quality Characteristics and Subcharacteristics" (ISO, 1991). It is important to note that a typical CBA system is composed by:

A Test Management System (TMS) - i.e. a tool providing the instructor with an easy to use interface, the ability to create questions and to assemble them into tests, the possibility of grading the tests and making some statistical evaluations of the results.

A Test Delivery System (TDS) - i.e. a tool for the delivery of tests to the students. The tool may be used to deliver tests using paper and pencil, a stand-alone computer, on a LAN, or over the web. The TDS may be augmented with a webenabler used to deliver the tests over the Web. In many cases producers distribute two different versions of the same TDS, one to deliver tests either on single computers or on LAN, and the other to deliver tests over the web. 
The TMS and TDS modules may be integrated in a single application or may be delivered as separate applications. Thus, it is of fundamental importance to devise a set of quality factors that can be used to evaluate both the modules belonging to this general structure of a CBA system."

Another journal entitled "Information Technology for Assessing Student Learning" by Salvatore Valenti discussed that "Assessment plays a central role in the educational process. In the last few years, the scientific community has seen the development of new assessment methodologies and novel tools applying Information Technology to the assessment process of student learning.

According to the findings (Valenti, Cucchiarelli, \& Panti, 2002), more than fifty commercial off-the shelf tools for Computer Based Assessment are currently available on the market. This number may rise considerably if we take into account the research tools currently under development and the tools for delivering assessment embedded within most electronic learning environments.

There are a number of reasons for this growing interest by research and industry in applying IT to the assessment of student learning. First, there is the increase in the number of students attending institutions of higher education. Most universities offer a portion of their required freshman classes in lectures of hundred or more students. Bjedov (cited in Valenti, Cucchiarelli, \& Panti, 2001) reports about teaching programming in a class whose enrolment varies between 360 students in spring semesters and 940 students in fall semesters. At the University of Ulster class sizes in excess of 100 are common for popular entry level modules in computer programming. Similar numbers are reported in Italy at the Universities of Ca' Foscari (Venice) and Ancona, and in Brazil at the University of Pernanbuco leading to the conclusion that the rising size and the diversity of teaching groups in high level education is a worldwide problem (Valenti et al, 2001).

Second, the growth of credit-bearing distance learning offerings and enrolments at accredited, degree granting colleges and universities has been astonishing in the last few years. During the academic year 1997-98, approximately 1.6 million students were enrolled in credit-bearing distance learning courses (whether electronic, television-based, or print- and-mailbased, and including both synchronous and asynchronous instruction) in degree-granting post-secondary colleges and universities in the United States. That year, 54,000 college-level credit-bearing distance-learning courses were offered in 1,680 institutions. Thirty-five states currently operate virtual universities or participate in a regional virtual university, typically created by existing degree-granting colleges and universities (Valenti, Panti, \& Leo, 2003). This growth raises the demand for reliable and effective tools for Computer Based Assessment."

The two (2) journals cited above are related to this study in such a way that the focus is on how assessment, using information technology impacts students or learners around the globe. The findings stated in both journals emphasized that computer-based assessments are truly in demand for reliable and effective delivery and administration of exams to students or learners.

The journal entitled "Computer-based, online summative assessment in undergraduate pharmacy teaching: The Manchester experience" by Harmesh Aojula, Jill Barber, Rod Cullen, \& Julie Andrews stated that "Computer-based assessment (CBA) has many advantages for staff and students in higher education. Although we have successfully used diagnostic and formative CBA for a number of years, the introduction of summative assessments raised additional concerns about development time, academic rigour, security and organisation. To explore these issues, a pilot study was set up to assess the running of online (summative) CBA for 240 students taking a first year course in Cell Biology and Biochemistry. We have compared the scores obtained from computer-based marking, with those obtained from: (a) optical mark readers; and (b) traditional hand-marking of scripts. Computer-based marking of text matching questions was initially compromised by spelling errors but these were reduced to an acceptable (1\%) level by introducing an online subjectspecific list of correctly-spelled options. The development and evaluation of secure online examination procedures is also discussed.

We conclude that, with these improvements, online CBA can be used successfully for a range of summative assessments in undergraduate Pharmacy courses."

Another journal entitled "Online Assessment: Perspectives Of Developers" by Karen Billings stated that "The topic of assessment is hot in education right now. High stakes testing, which links test scores to school funding, is now part of the job of school administrators. The No Child Left Behind (NCLB) Act requires states to test students in more grades more often to prove they are meeting national achievement standards. These tests must be aligned with the state's academic standards, which can vary in their requirements from NCLB. Test results are being used to hold educators, schools and districts accountable for student achievement. Assessment is one of the fastest growing segments in education publishing. Online assessments are computer-based tests that automatically score student tests. Most include extensive reporting features and suggestions for remediation. In order to facilitate discussion between educators and companies, the Software and Information Industry Association (SIIA) surveyed top computer-based assessment vendors to learn how they have changed to meet the growing demand for online assessments. The survey included a question about the trends the vendors see concerning online assessments."

The journal entitled "Improving Student Performance Through Computer-based Assessment: insights from recent research" by C. Ricketts and S. J. Wilks, stated that "One of the benefits claimed for computer-based assessment is that it can improve student performance in summative assessments. During the introduction of computer-based assessment in a first-year module on numeracy and statistics in Biology, online assessment was used to replace OMR-marked multiplechoice tests. Analysis of student results after the first year (Ricketts \& Wilks, 2001) showed that students using online assessment did not perform as well as those using OMR-marked multiple-choice questions. The difference in performance could not be attributed to a weaker student cohort. In the second year student performance improved dramatically when 
they were not required to scroll through the question paper. Our results suggest that students may be disadvantaged by the introduction of online assessment, unless care is taken with the student-assessment interface."

\section{METHOD}

\section{- Research Design}

Web page development is a broad term for activities related to developing a web site for the World Wide Web or an intranet. This can include e-commerce business development, web design, web content development, client-side/serverside coding and web server configuration. However, among web professionals, "web development usually refers only to the non-design aspects of building web sites, e.g. writing mark-up and coding. Web development can range from developing the simplest static single page of plain text to the most complex web-based internet applications, electronic businesses, or social network services.

For larger businesses and organizations, web development teams can consist of hundreds of people (web developers). Smaller organizations may only require a single permanent or contracting web master or secondary assignment to related job positions such as graphic designer and/or information systems technician. Web development may be a collaborative effort between departments rather that the domain of a designated department.

Web page development entails a lot of designing and coding and this can be achieved by using a programming language especially designed for this purpose which is HTML.

Hypertext Mark-up Language (HTML) is currently the predominant presentation level standard for constructing World Wide Web documents. It enables the users to move between different documents or parts of the same document easily. Being a "mark-up language", i.e. a computer language that describes how a page should be formatted, HTML allows the web page designer or programmer to change fonts, add colors, create headlines and embed graphics in a web page with much convenience by using symbols which are called Tags. These tags may be inserted into the HTML code either manually or by using an HTML editor to automatically create them.

In addition to HTML, to make the web site dynamic, PHP was also used. PHP originally stood for Personal Home Page but as its usefulness and capabilities grew, PHP came to mean Hypertext Preprocessor. PHP was embedded in HTML and is a scripting language which means that it is designed to do something only after an event occurs.

Since the "Online Exam Maker and Checker" is handling a large volume of data for creating and managing classes as well as creating and deploying examinations, it required a large storage in a form of a database. A database is a repository of interrelated data organized by software called Database Management System (DBMS). For this purpose, MySQL was of great use. MySQL is a database management system which is technically an application that manages files in a database.

In order to complete the design and development of the software, the authors created the web page using a text editor like Notepad or other specialized HTML editor available. Further, to upload the created web page, the authors considered either a paid web hosting service or the traditional FTP client.

Further, for documentation purposes, the authors used a tool to aid them in the designing phase. Flowcharts were created to help in the visual organization of the content and for finding flaws in the process if there is any.

\section{- Participants}

In the completion of this study, the following people were deemed to play very important roles.

The authors, in particular the web designers are responsible for the layout of the entire web page and the web programmer was responsible for the coding and testing. The final output is expected to be as user-friendly as possible and easy to access and manage as well.

The end-users are the faculty members and students of Lyceum of the Philippines University. The faculty members were given their own accounts to access the program, to create and generally manage their classes and to create and administer online exams. Students, on the other hand, were enrolled by their instructor in the particular class and were given their own accounts also.

The exams are to be created by the instructor through the use of the program which is readily accessible by the enrolled students once the particular exam has been activated. After which, the students were able to view their scores in the grade book which is also accessible by the instructor for the purpose of computation of grades.

\section{- Data Analysis}

Part of the design phase was the use of the flowchart that served as a schematic representation of the program flow. This was an important part of the web development process since in here; the processes were visually presented for easier understanding. 


\section{RESULTS}

After the design and development of the Online Exam Maker and Checker as a part of the IVLE inside the Lyceum of the Philippines University web page, the following flowcharts and screen shots were provided to discuss the functions of each major part.

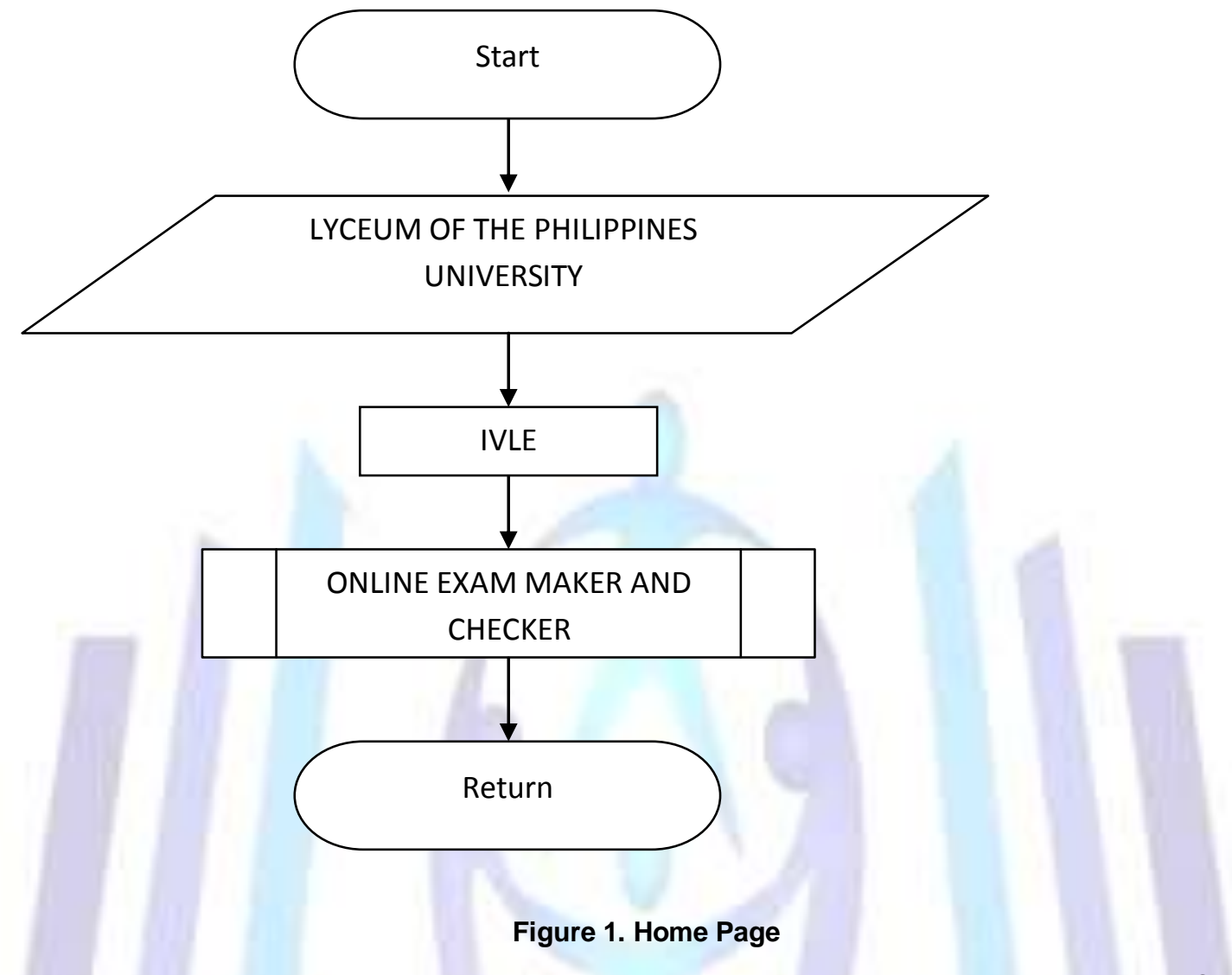

Figure 1 shows the Home Page wherein the user can only access the Online Exam Maker and Checker upon accessing the Lyceum of the Philippines University Batangas Campus Web Page. 


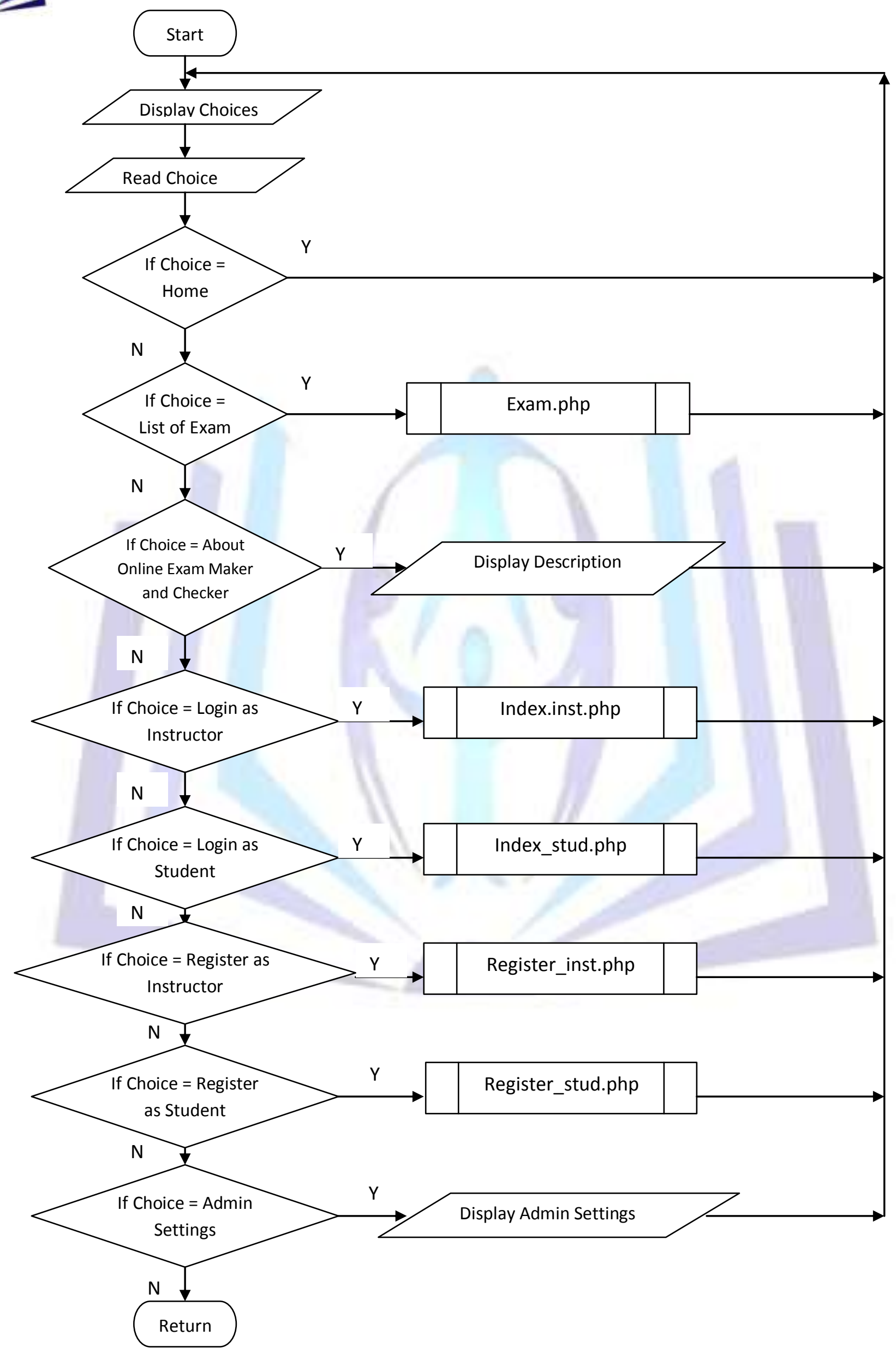


Figure 2. Index Page

Figure 2 shows the major links on the Online Exam Maker and Checker page. These links allow the user to select options when the system is accessed. It contains options namely view list of exams which when selected will display a list of all exams created and activated. The About Online Exam Maker and Checker link, when clicked, displays details about the system. If, on the other hand, the user would like to login, he has to register first to create his account and if the registration is successful, the user can then login. The user may register whether a student or an instructor. Login options are student login, instructor login and Admin.

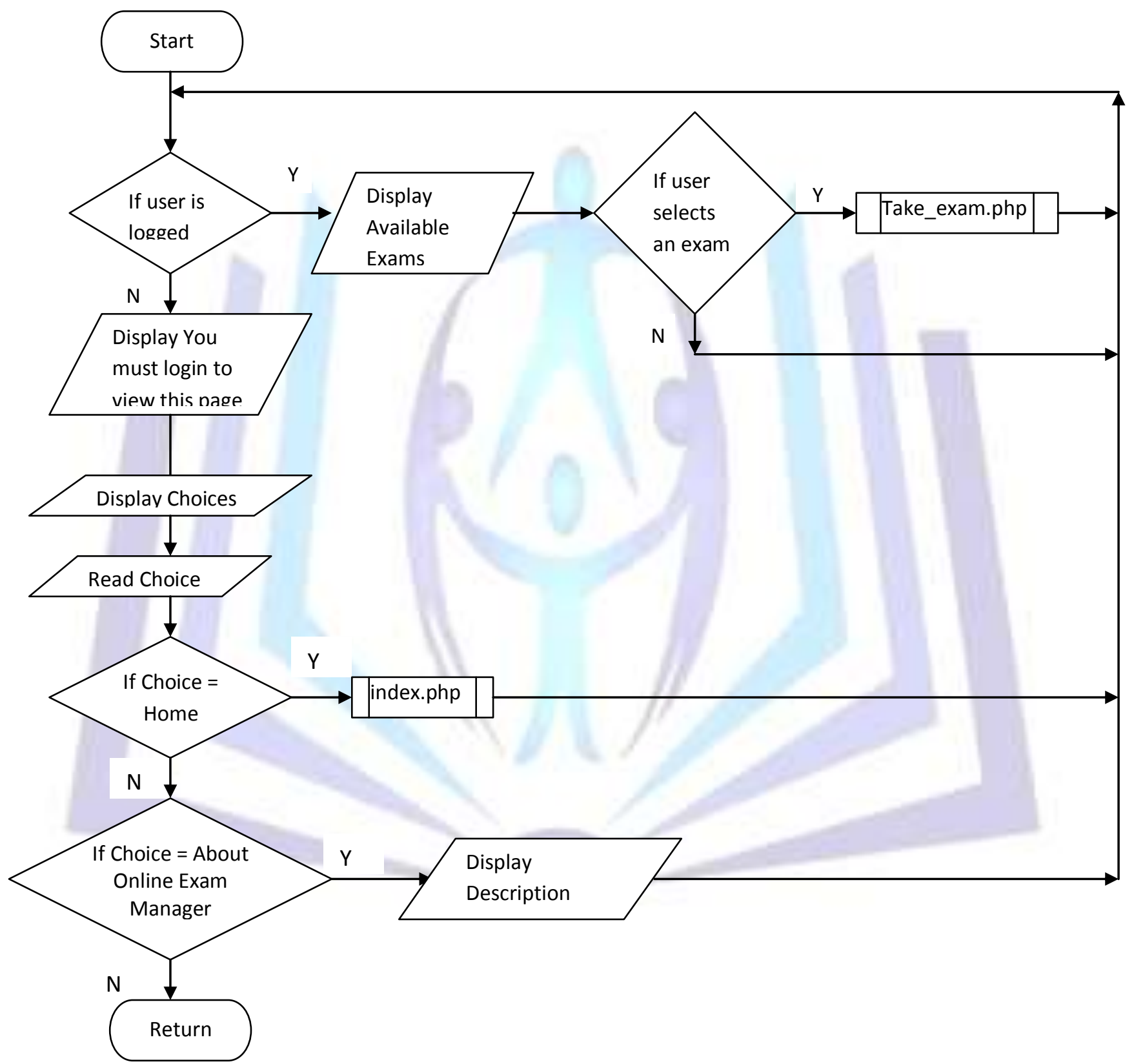

Figure 3. Exam

This figure shows the sub links if the Exam link in the Index page is clicked. The user can then have the option whether to view only the list of available exams or to take an activated exam. If the user selects Home link, it will be redirected to the Online Exam Manager home page. On the other hand, when the About Online Exam Manager link is clicked, a description about the system will be displayed. 


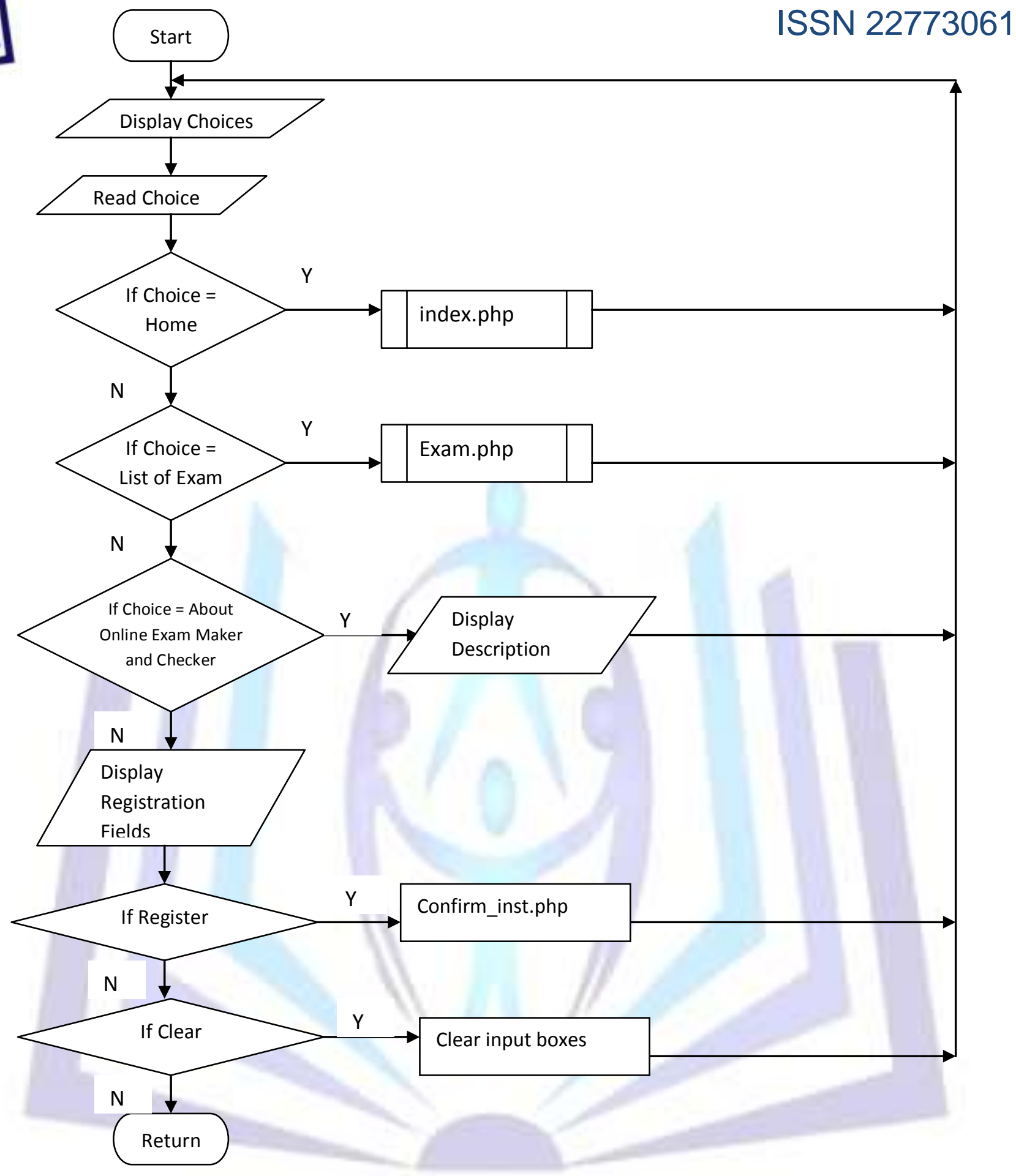

Figure 4. Register_inst.

This figure shows the Registration process to which the user will be directed to when the Register as Instructor link is clicked on the Index page. If the user selects Home link, it will be redirected to the Online Exam Maker and Checker home page. On the other hand, when the About Online Exam Maker and Checker link is clicked, a description about the system will be displayed. 


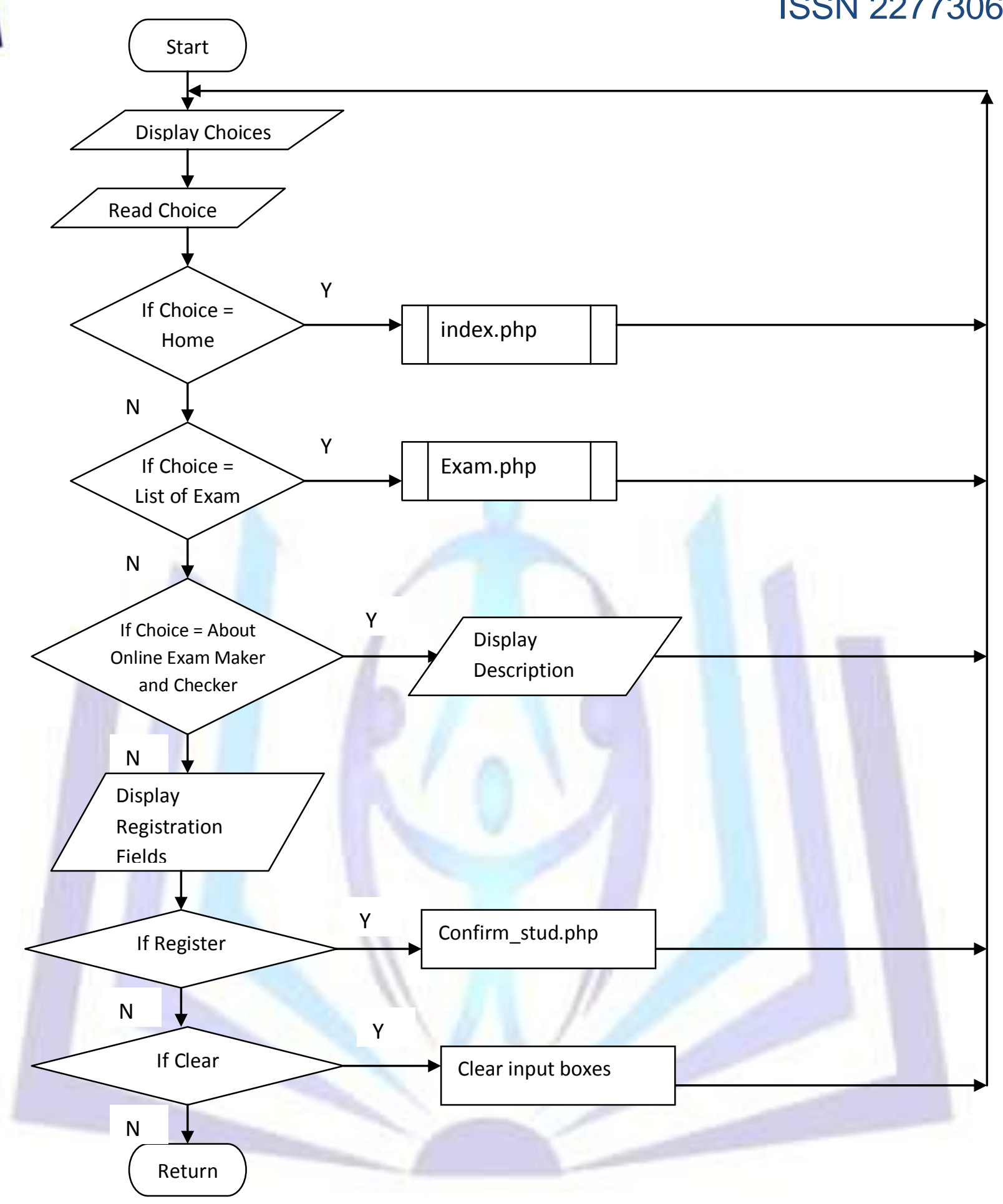

Figure 5. Register_stud

This figure shows the Registration process to which the user will be directed to when the Register as Student link is clicked on the Index page. If the user selects Home link, it will be redirected to the Online Exam Maker and Checker home page. On the other hand, when the About Online Exam Maker and Checker link is clicked, a description about the system will be displayed. 


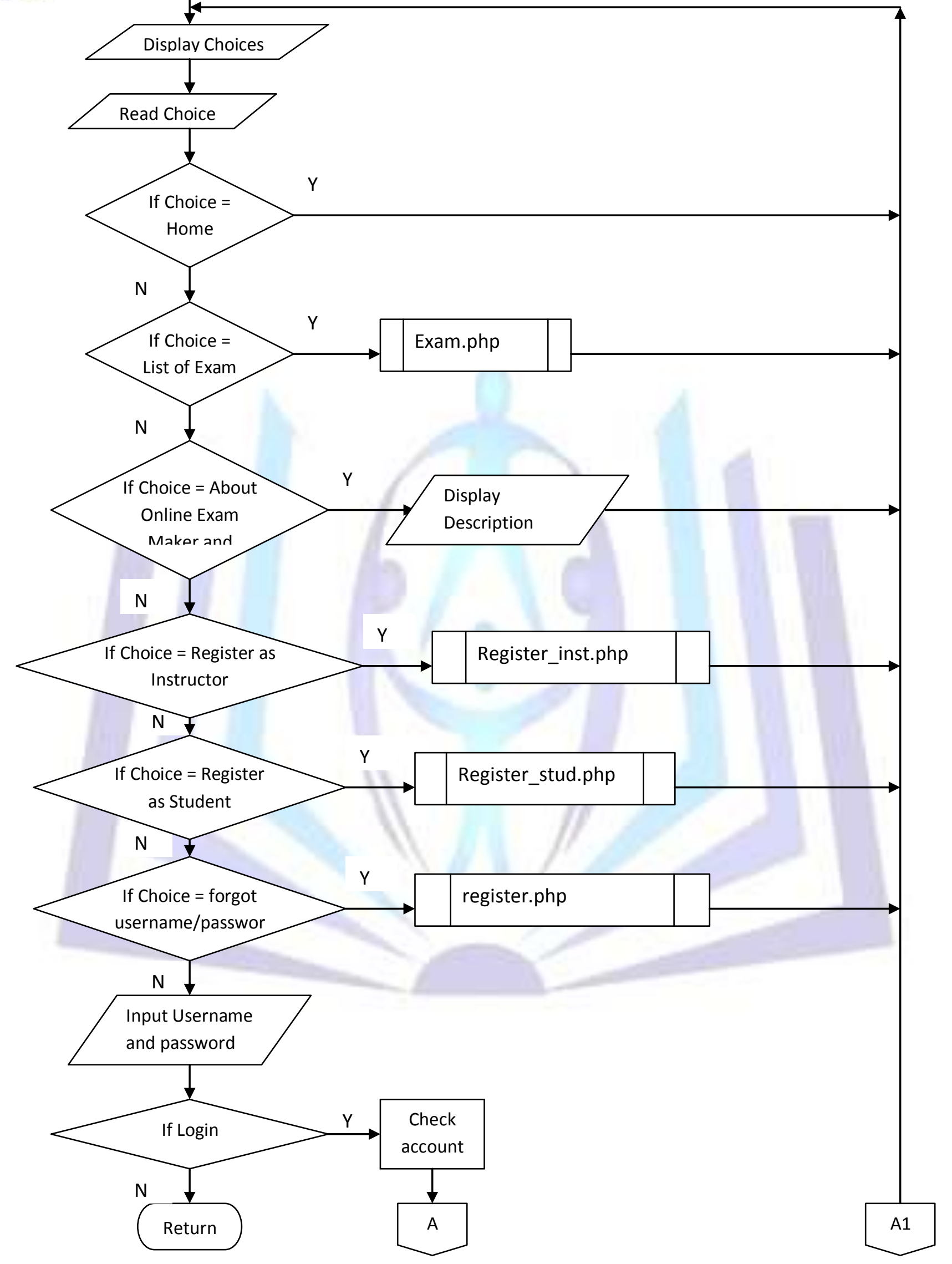

Figure 6. Index_inst 


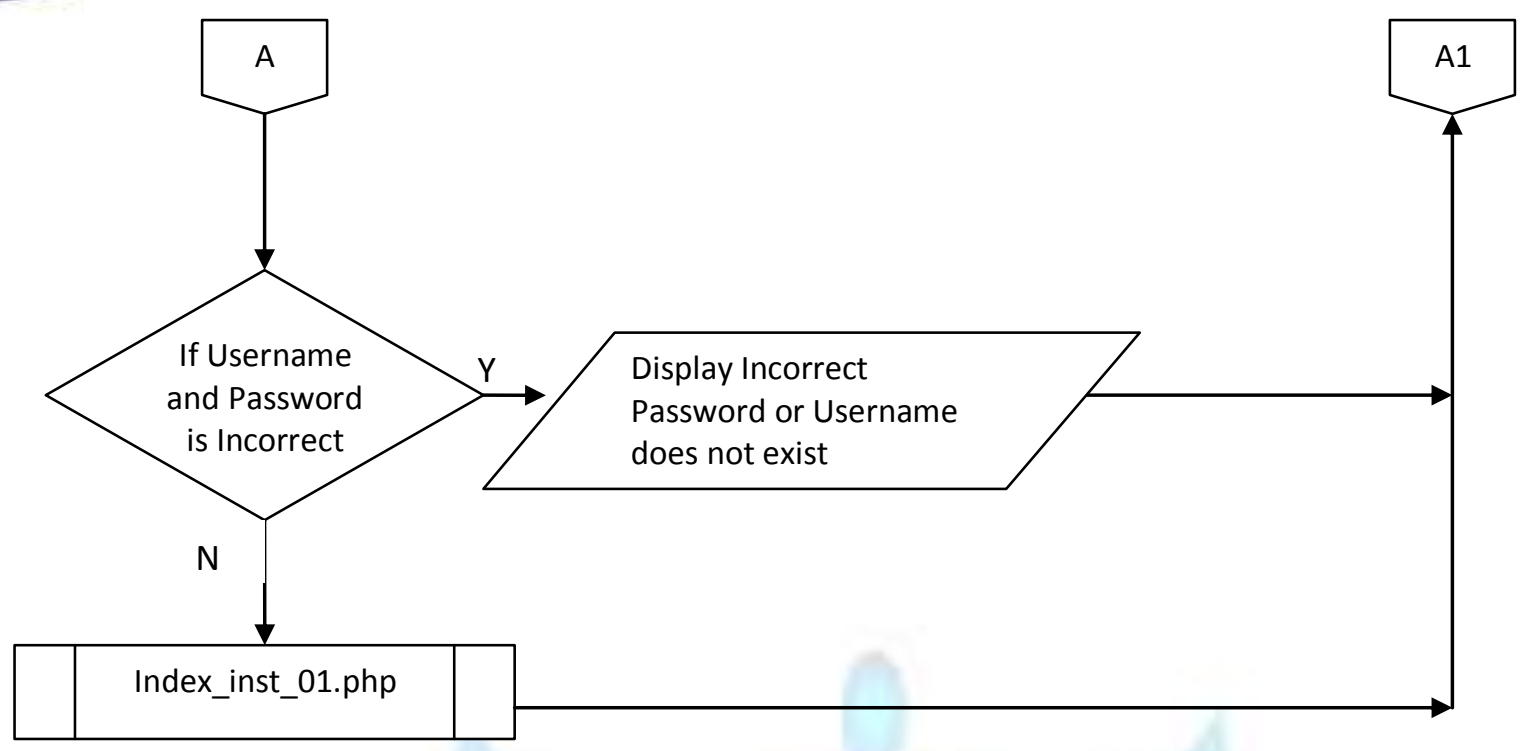

Figure 7. Index_inst continued

Figures 6 and 7 show the available links when the Login as Instructor link is clicked on the Index page. The entered Username and Password will be checked by the system. If either is incorrect, user access will be denied otherwise a new set of links will be displayed and available for use. If the user forgot his username and/or password, the change username/password link should be clicked where the user would be prompted to enter his new username and/or password. If the user selects Home link, it will be redirected to the Online Exam Maker and Checker home page. On the other hand, when the About Online Exam Maker and Checker link is clicked, a description about the system will be displayed. 


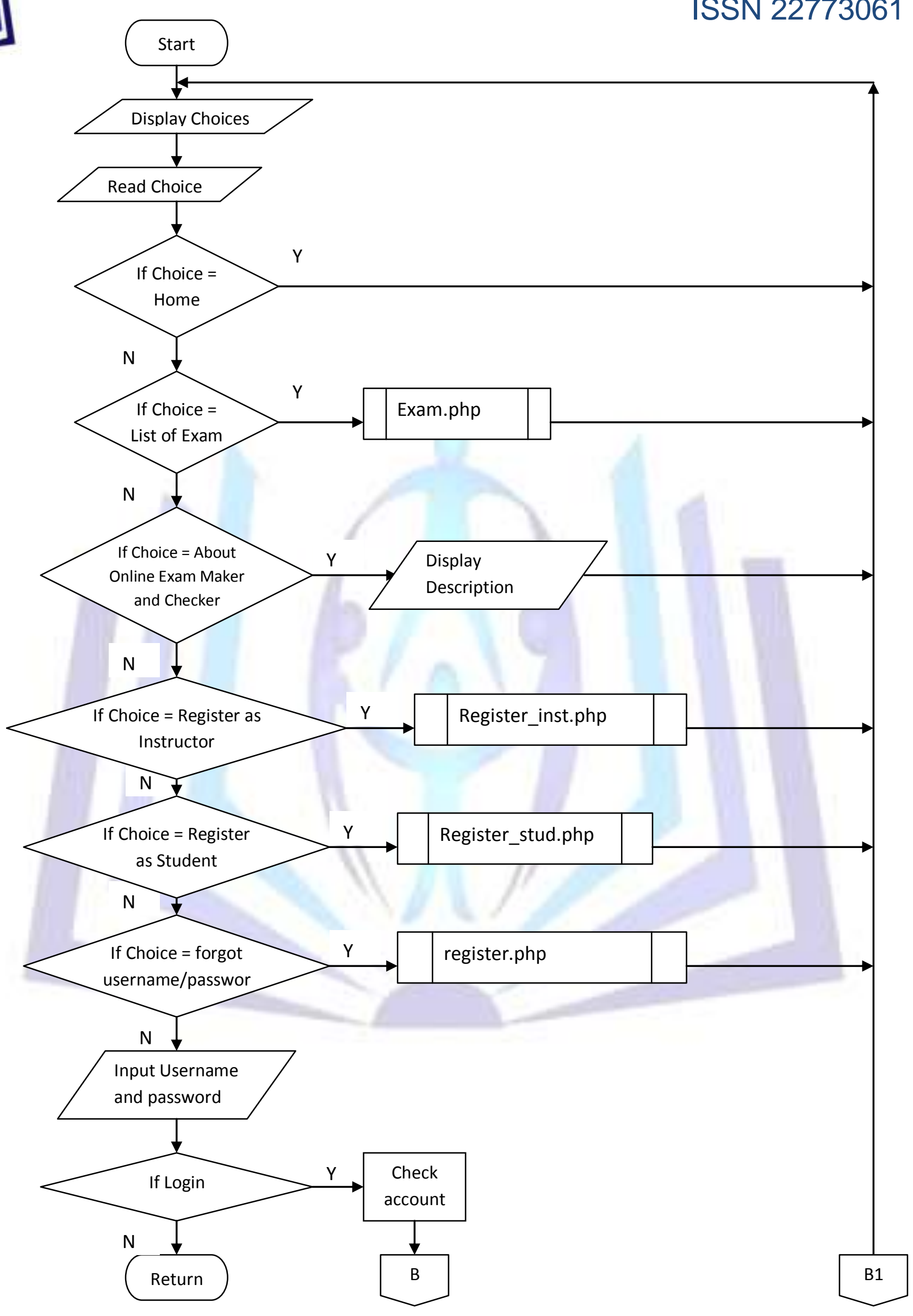

Figure 8. Index_stud 


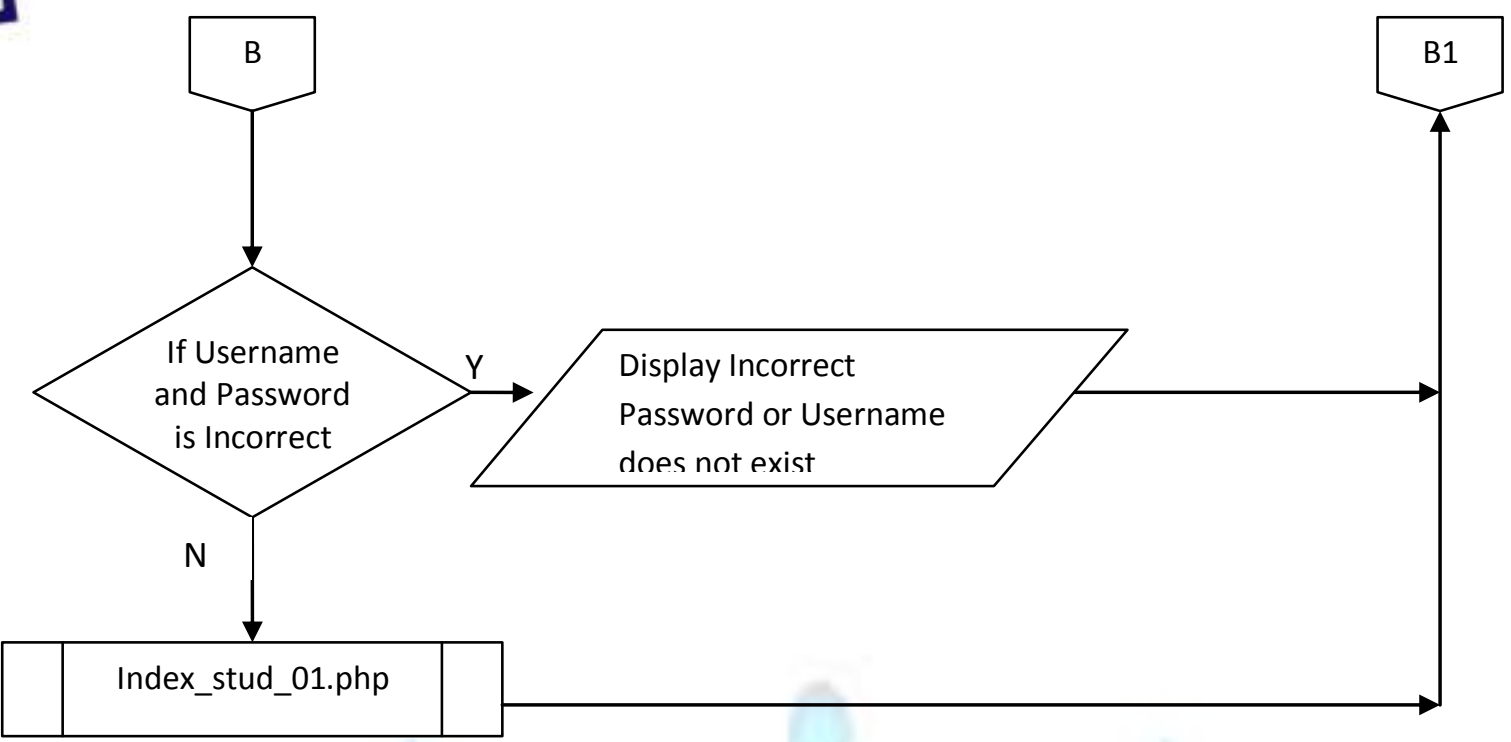

Figure 9. Index_stud continued

Figures 8 and 9 shows the available links when the Login as Student link is clicked on the Index page. The entered Username and Password will be checked by the system. If either is incorrect, user access will be denied otherwise a new set of links will be displayed and available for use. If the user forgot his username and/or password, the change username/password link should be clicked where the user would be prompted to enter his new username and/or password. If the user selects Home link, it will be redirected to the Online Exam Maker and Checker home page. On the other hand, when the About Online Exam Maker and Checker link is clicked, a description about the system will be displayed. 


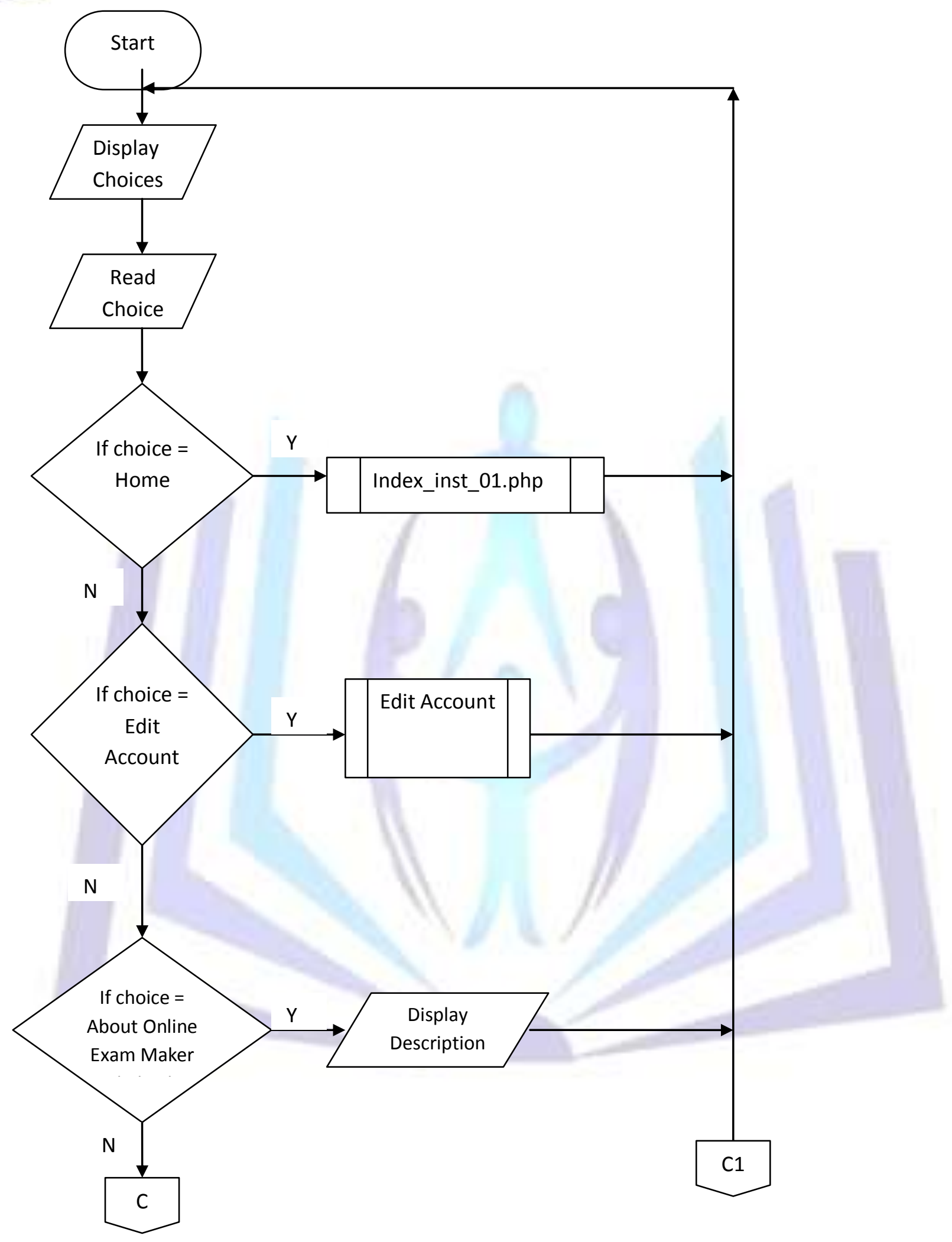

Figure 10. Index_inst_01 


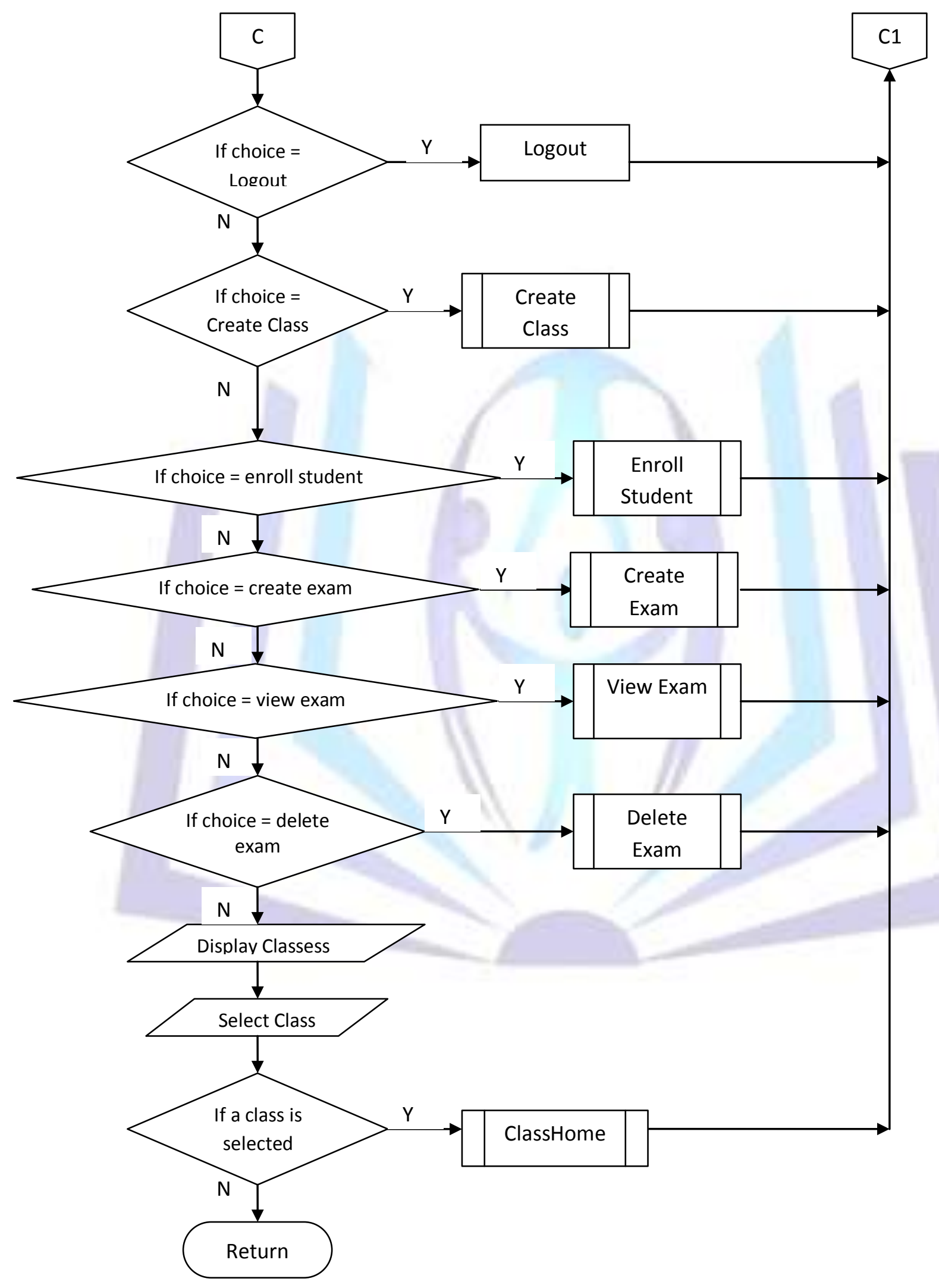


Figure 11. Index_inst_01 continued

Figures 10 and 11 show the available links when the Instructor has logged in correctly. The instructor is then allowed to do the following tasks. If the edit account link is clicked, he will be allowed to edit his profile, if the create class link is clicked, the instructor will be allowed to create his class or classes, if the enroll students link is clicked, the instructor can then select the students to be enrolled in the in the created class. The instructor can also create, view and delete exams if the create exam, view exam and delete exam links are clicked respectively. On the other hand, a link to go back to the class home page is also an option and if the instructor is done with the above actions, he may logout by clicking on the logout link. 


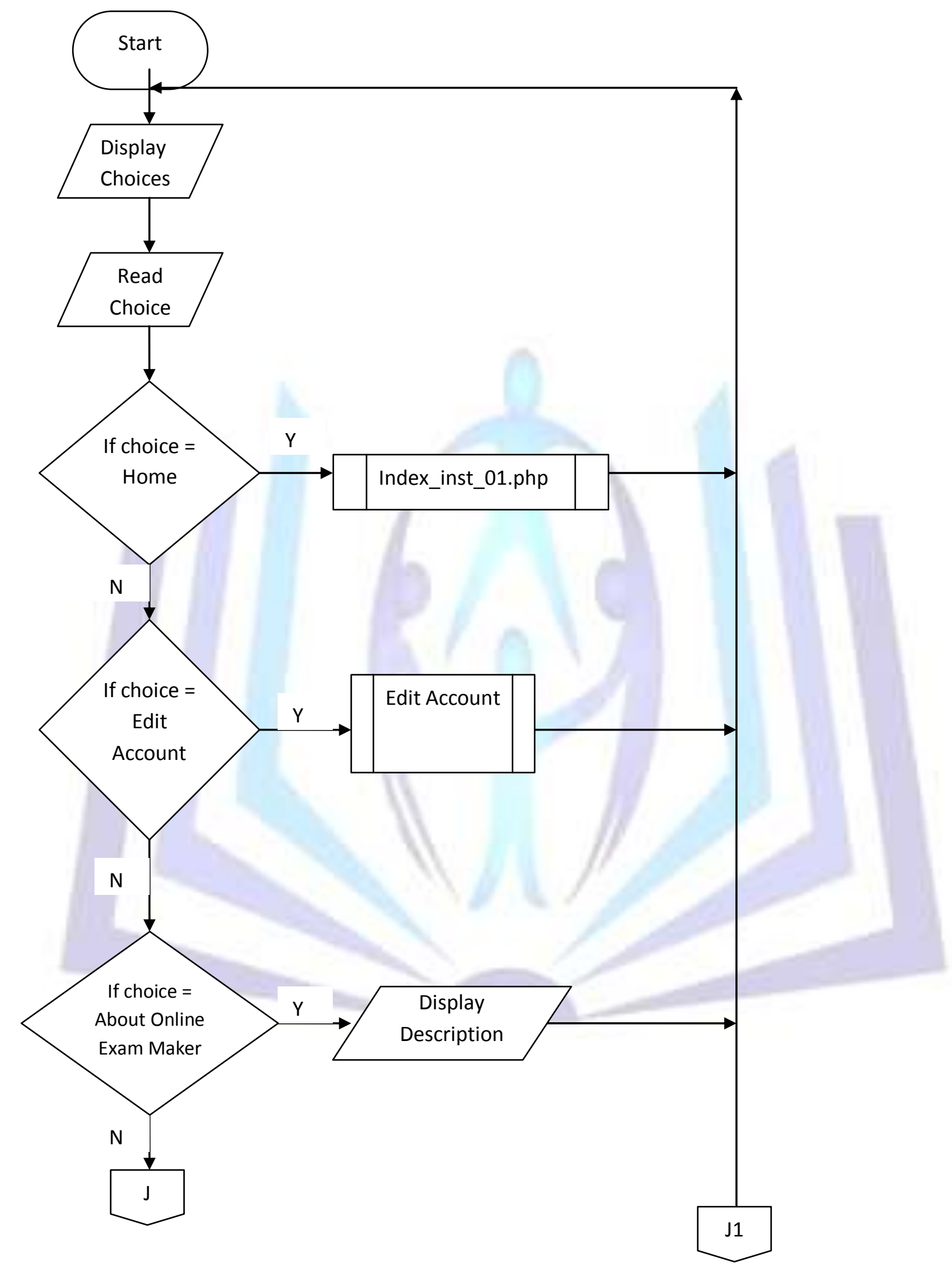

Figure 12. Index_stud_01 


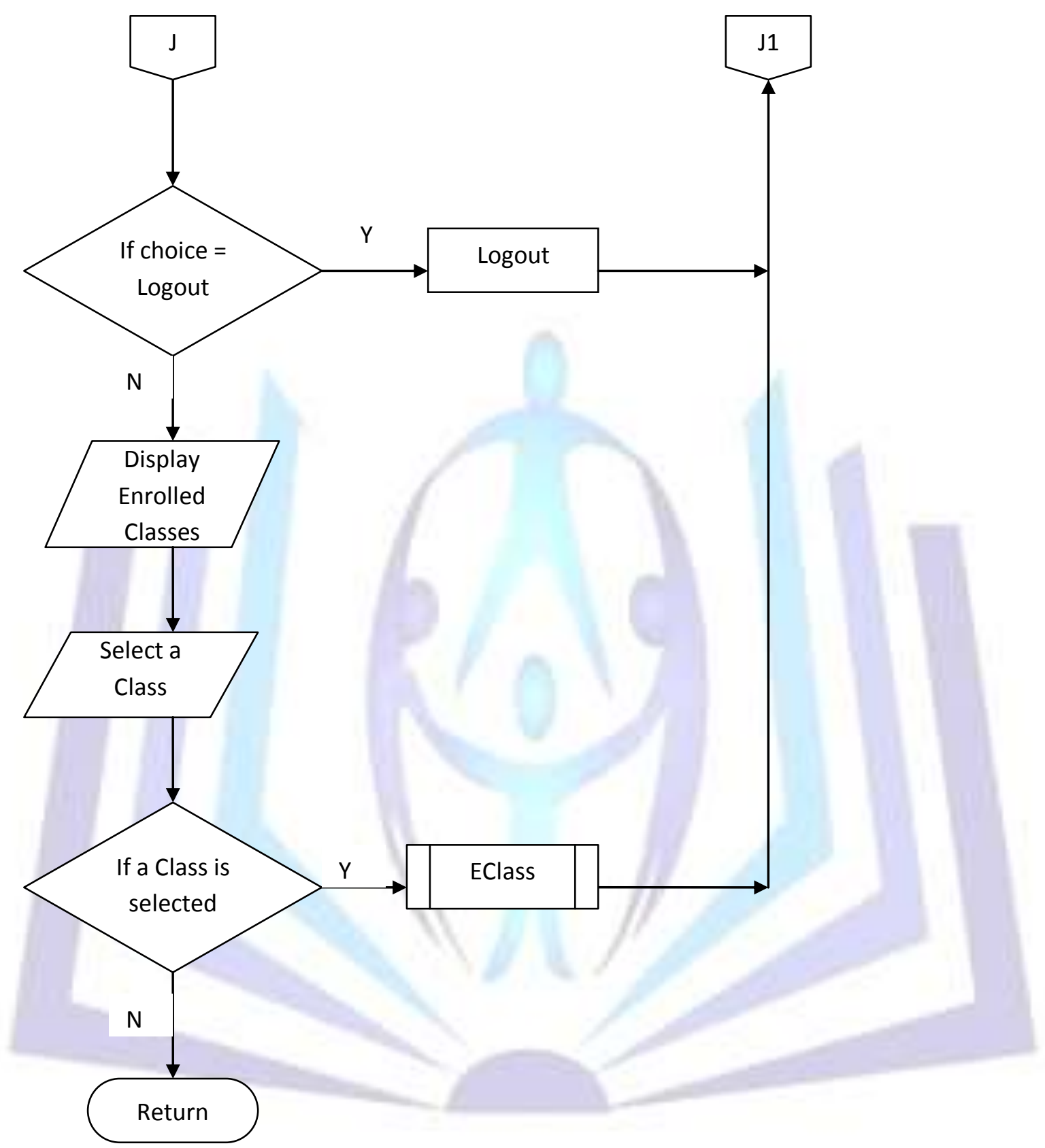

Figure 13. Index_stud_01 continued

Figures 12 and 13 show the available links when the Student has logged in correctly. The student is then allowed to do the following tasks. If the edit account link is clicked, he will be allowed to edit his profile, if the EClass link is clicked, the student will be able to view the classes in which he is enrolled. The student can also see a description about the Online Exam Maker and Checker and if the he is done with the above actions, he may logout by clicking on the logout link. 


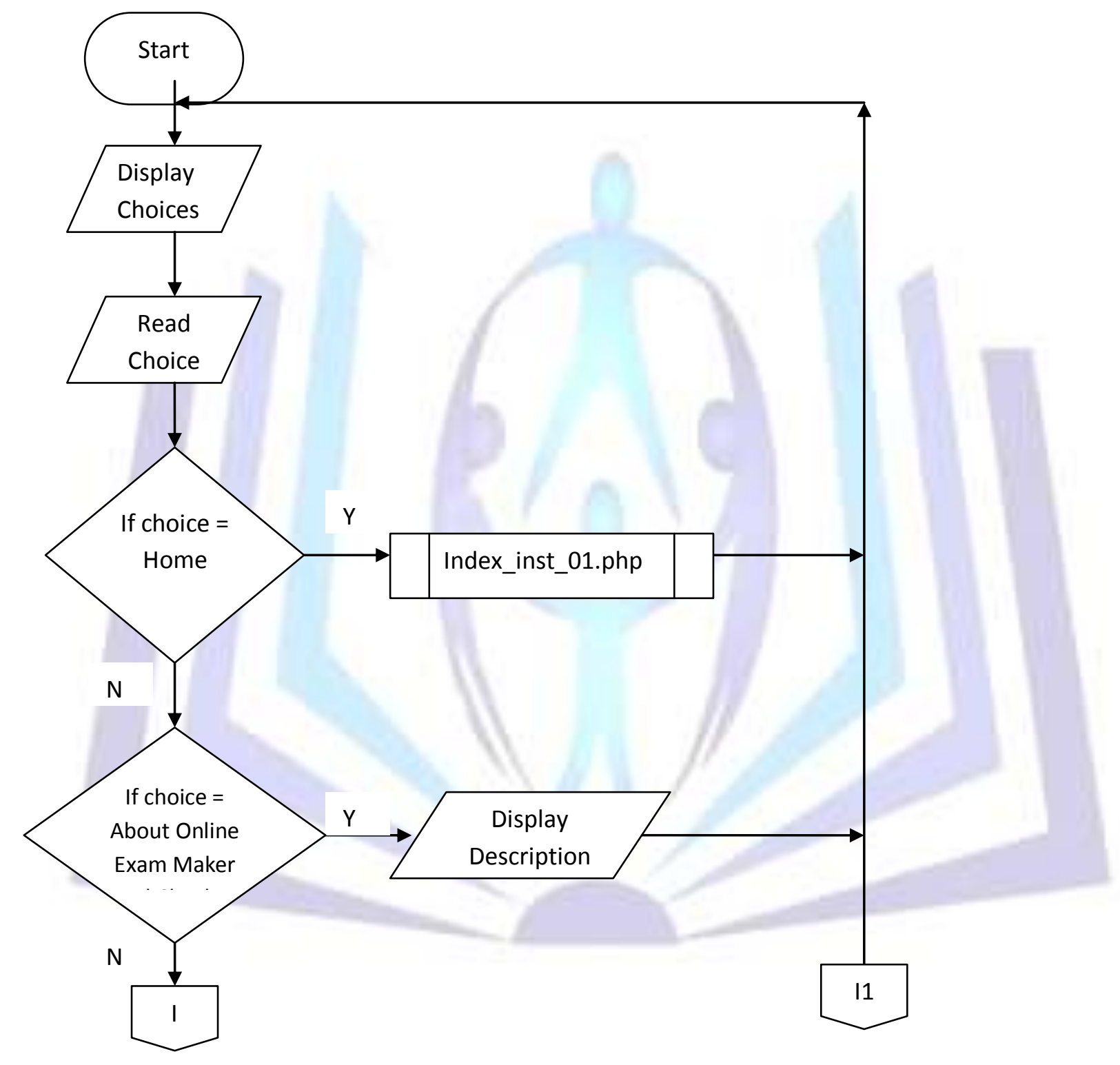

Figure 15. Edit Account 


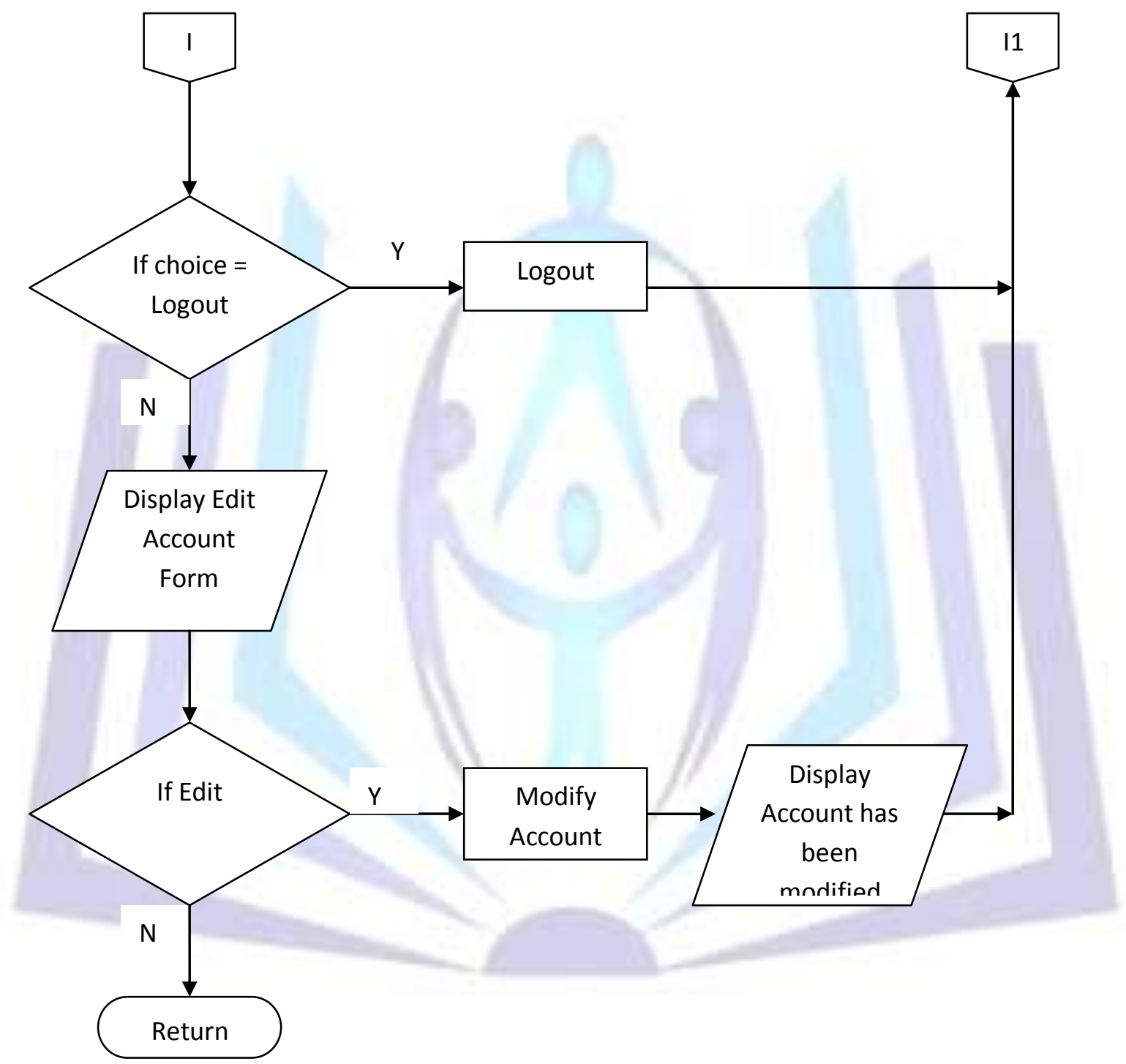

Figure 15. Edit Account continued

Figures 14 and 15 show the sub links when the Edit Account link is clicked. The user has two options whether to continue with the editing by clicking on the edit button or to cancel it. The user can also see a description about the Online Exam Maker and Checker if the About Online Exam Maker and Checker link is clicked and if he is done with the above actions, he may logout by clicking on the logout link. 


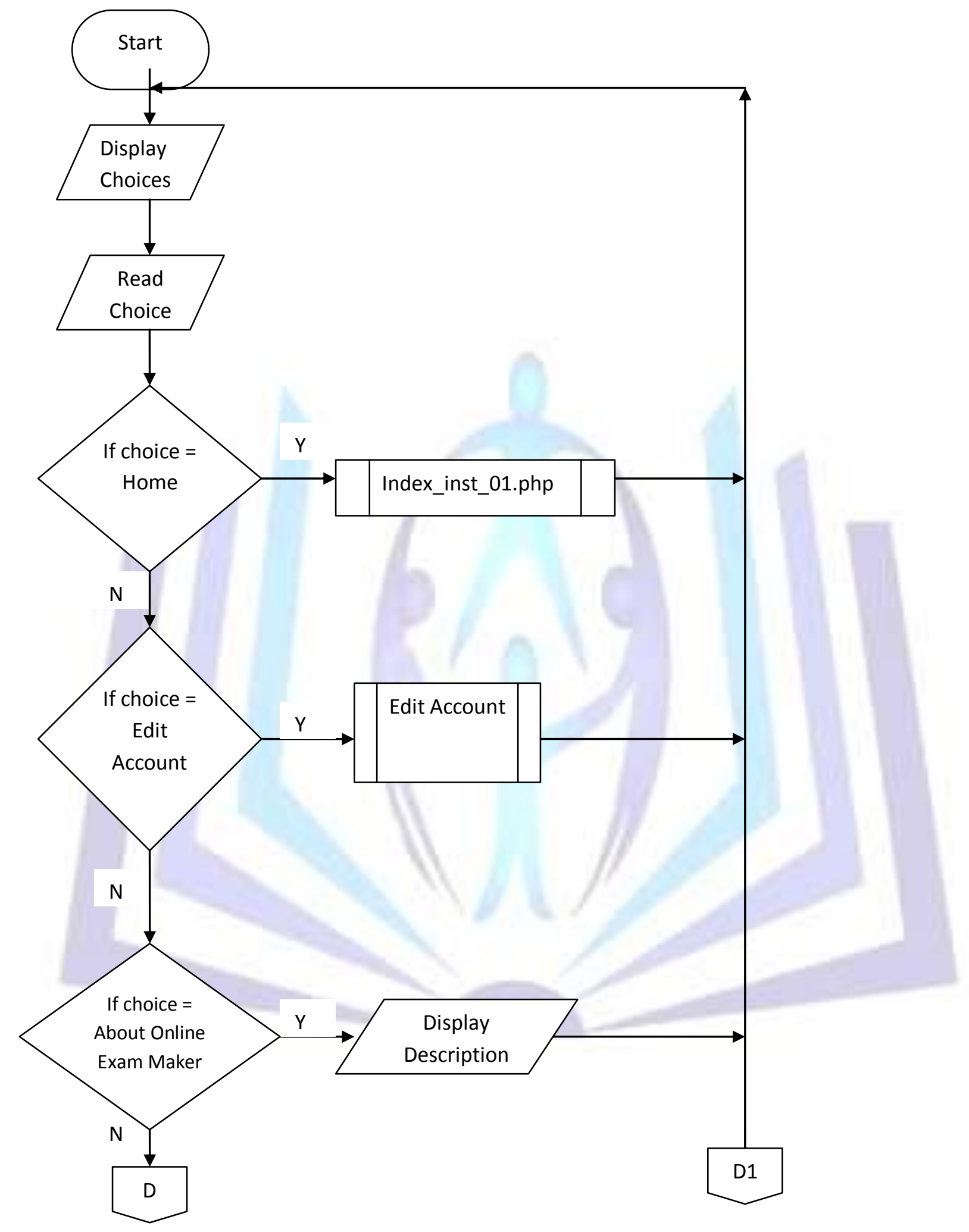

Figure 16. Create Class 


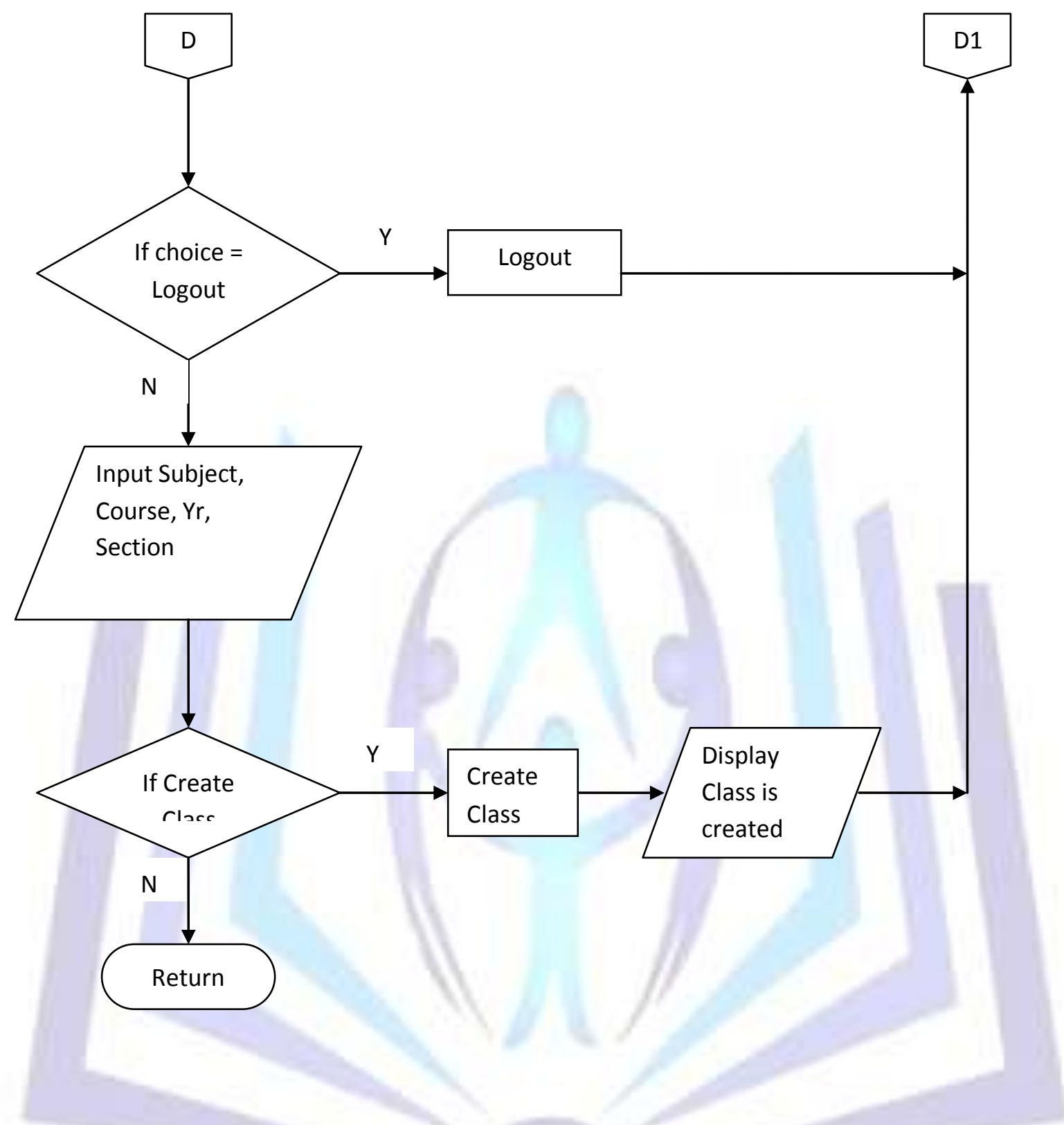

Figure 17. Create Class continued

Figures 16 and 17 show the sub links when the Create Class link is clicked. This option is available for instructors only. The instructor would need to enter the required details to complete the process or may cancel it, if needed. The user can also see a description about the Online Exam Maker and Checker if the About Online Exam Maker and Checker link is clicked and if he is done with the above actions, he may logout by clicking on the logout link. 


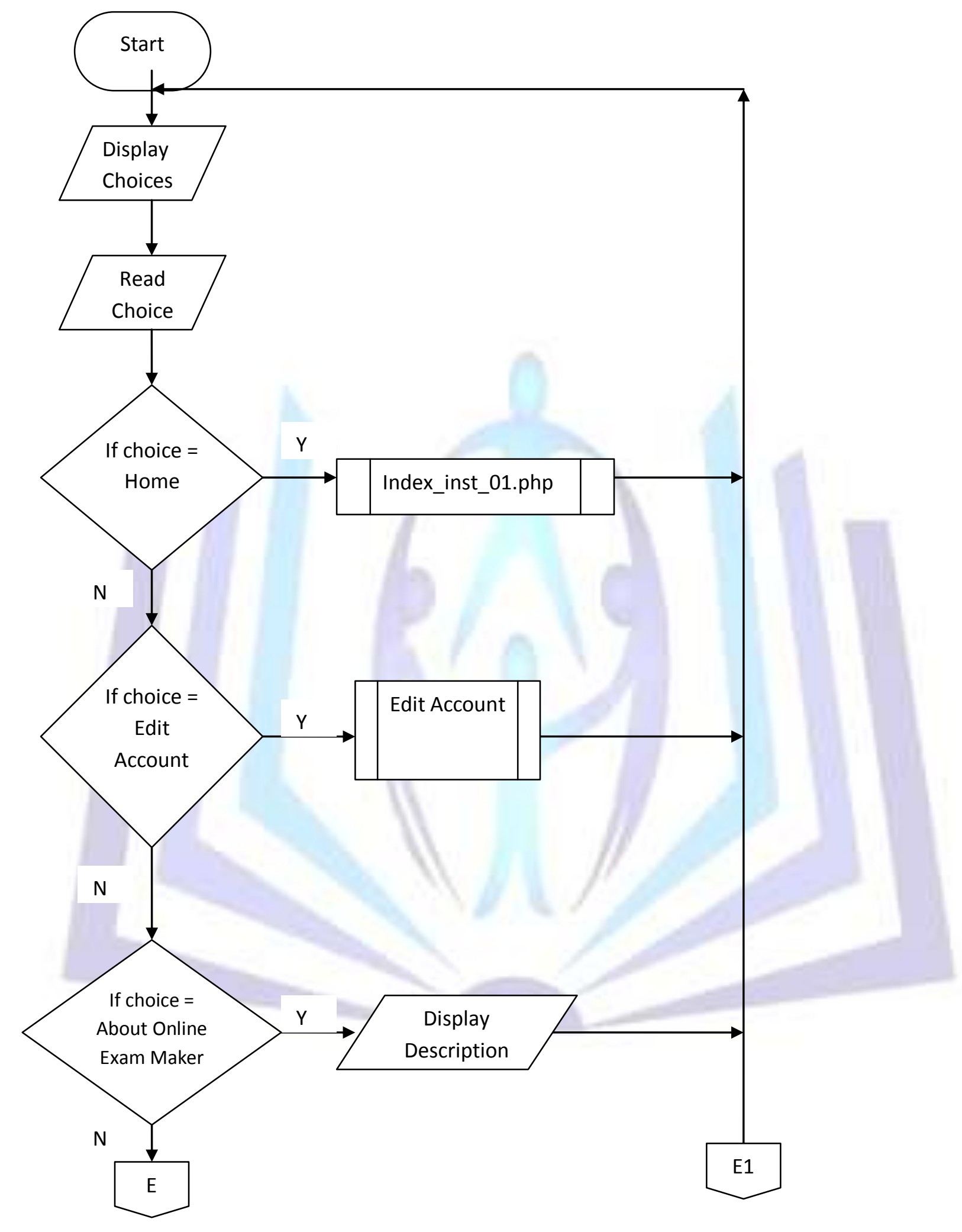

Figure 18. Enroll Student 


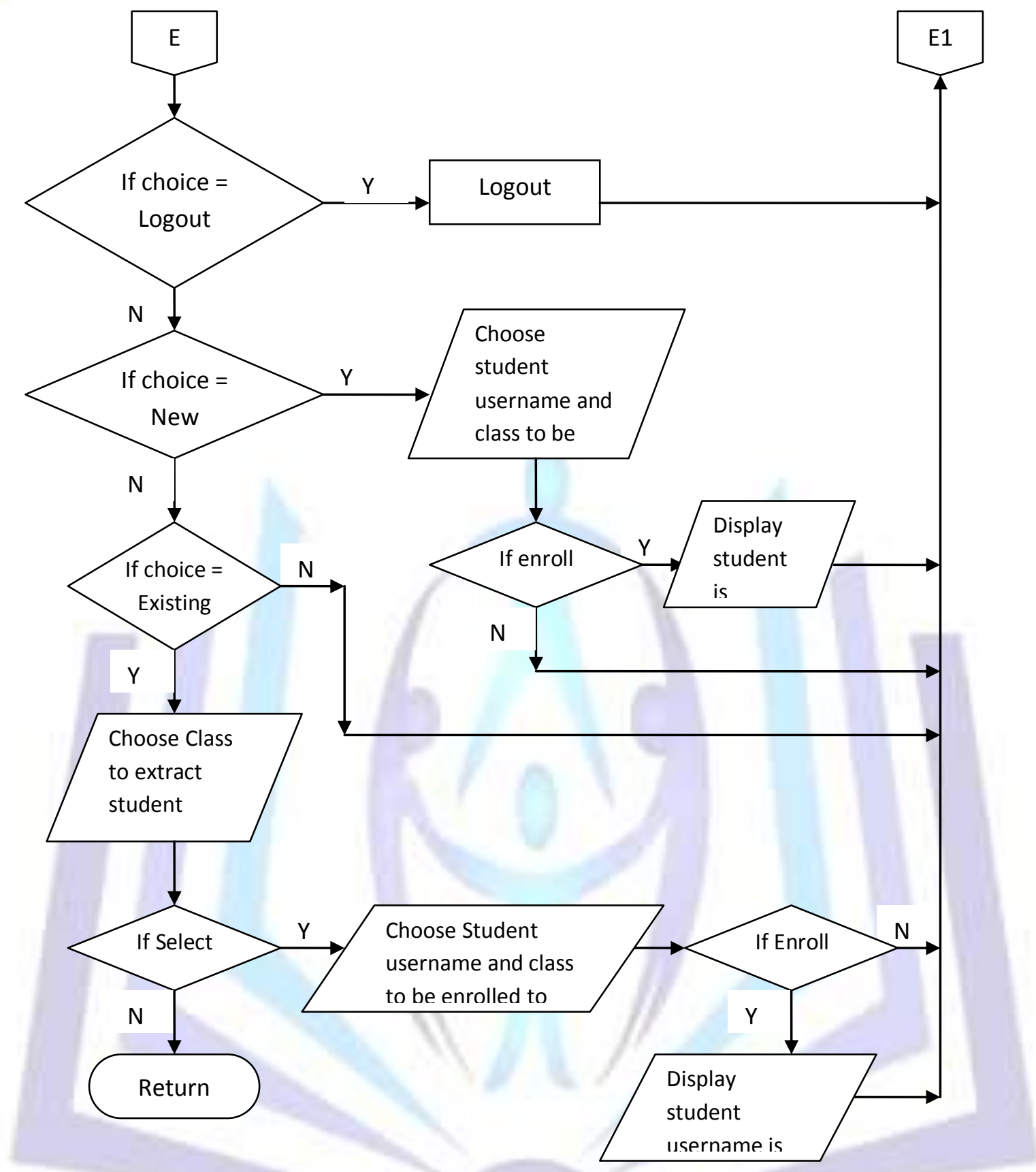

Figure 19. Enroll Student continued

Figures 18 and 19 show the sub links when the Enroll Student link is clicked. This option is available for instructors only. The instructor can use this link to enroll or unenroll students in the classes which he created by selecting the students' names from the list. The user can also see a description about the Online Exam Maker and Checker if the About Online Exam Maker and Checker link is clicked and if he is done with the above actions, he may logout by clicking on the logout link. 


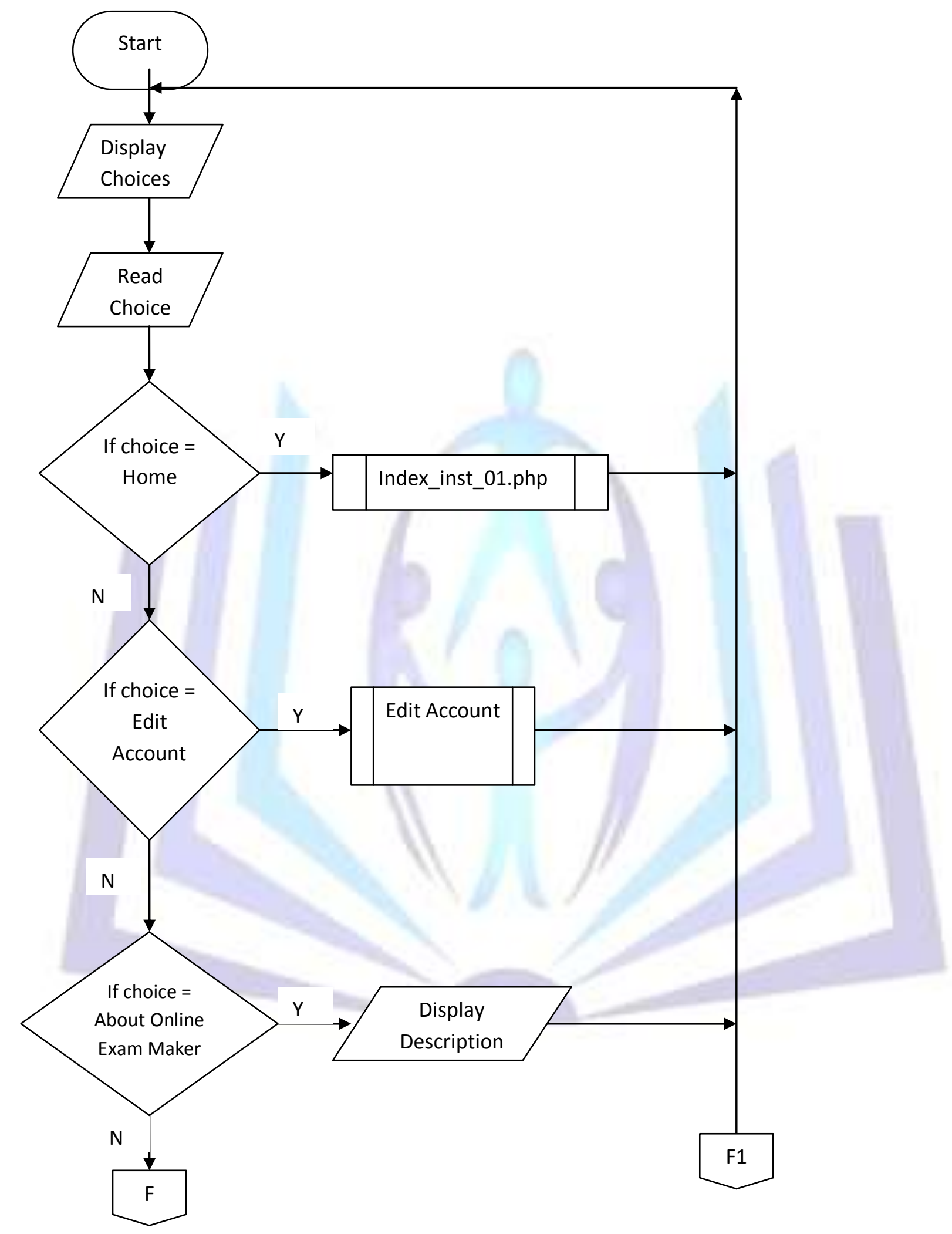

Figure 20. Create Exam 


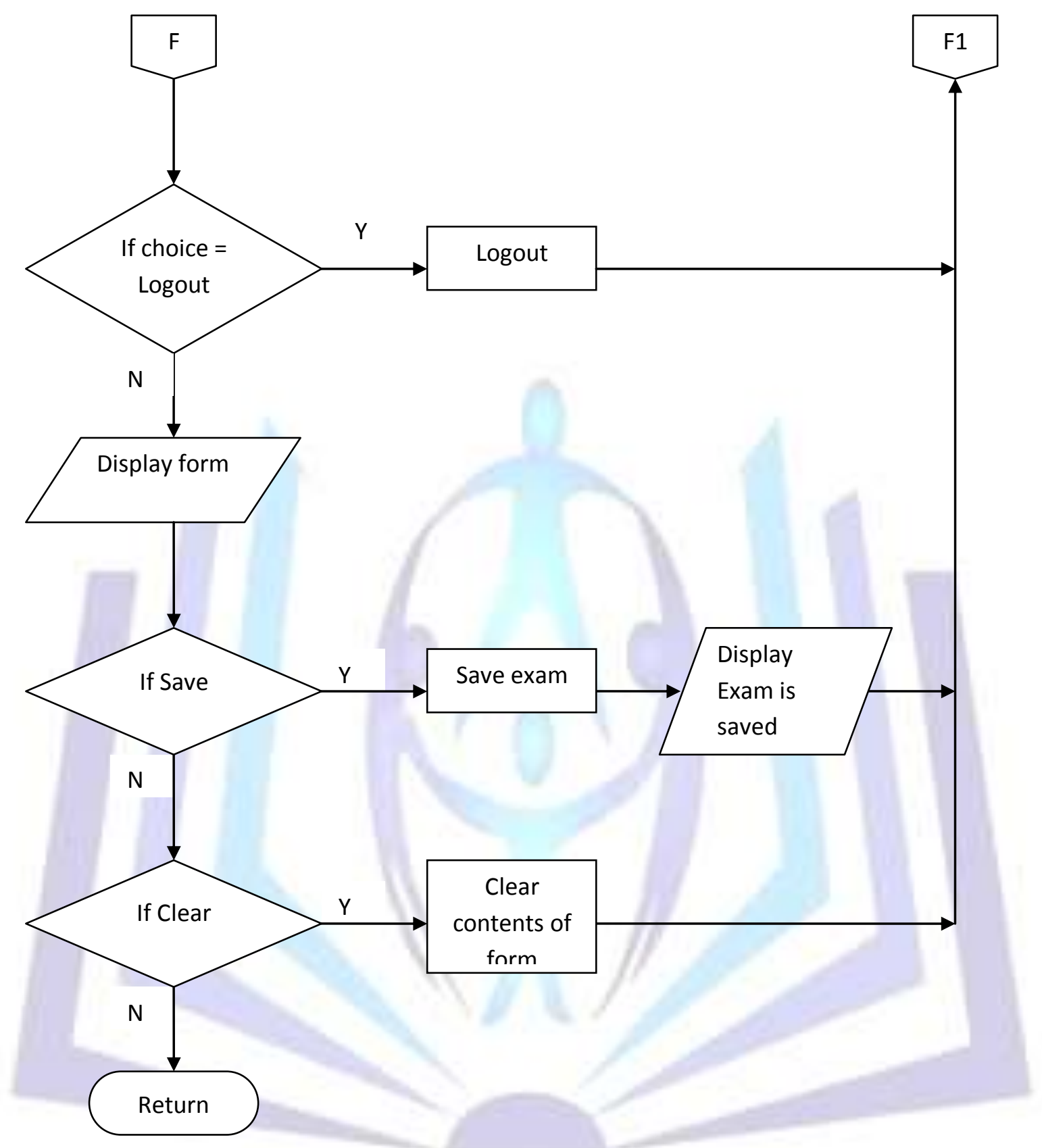

Figure 21. Create Exam continued

Figures 20 and 21 show the sub links when the Create Exam link is clicked. This option is available for instructors only. In this page, the instructor is enabled to enter the questions to appear in the exam as well as the question types and the markings to be used. The user can also see a description about the Online Exam Maker and Checker if the About Online Exam Maker and Checker link is clicked and if he is done with the above actions, he may logout by clicking on the logout link. 


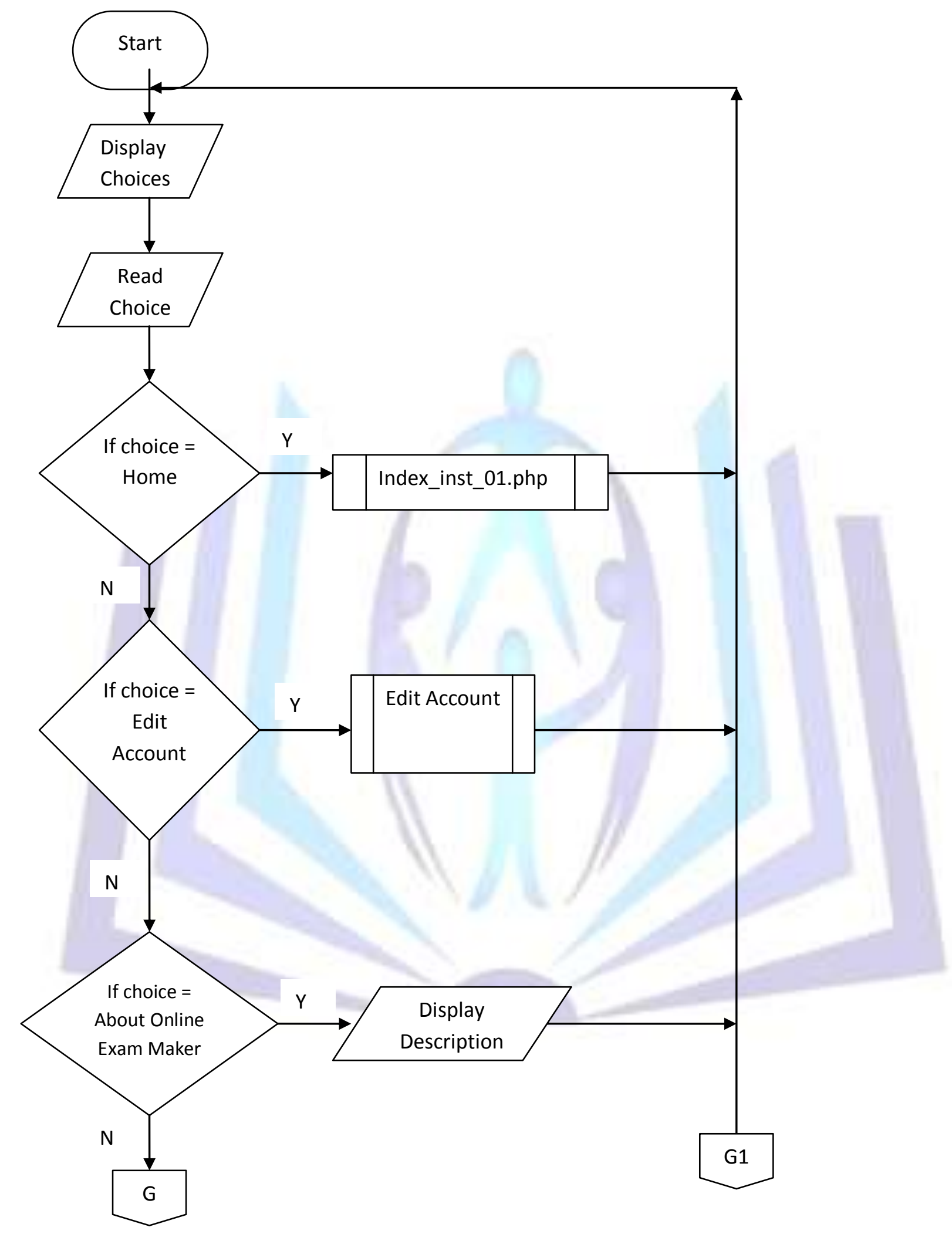

Figure 22. Delete Exam 


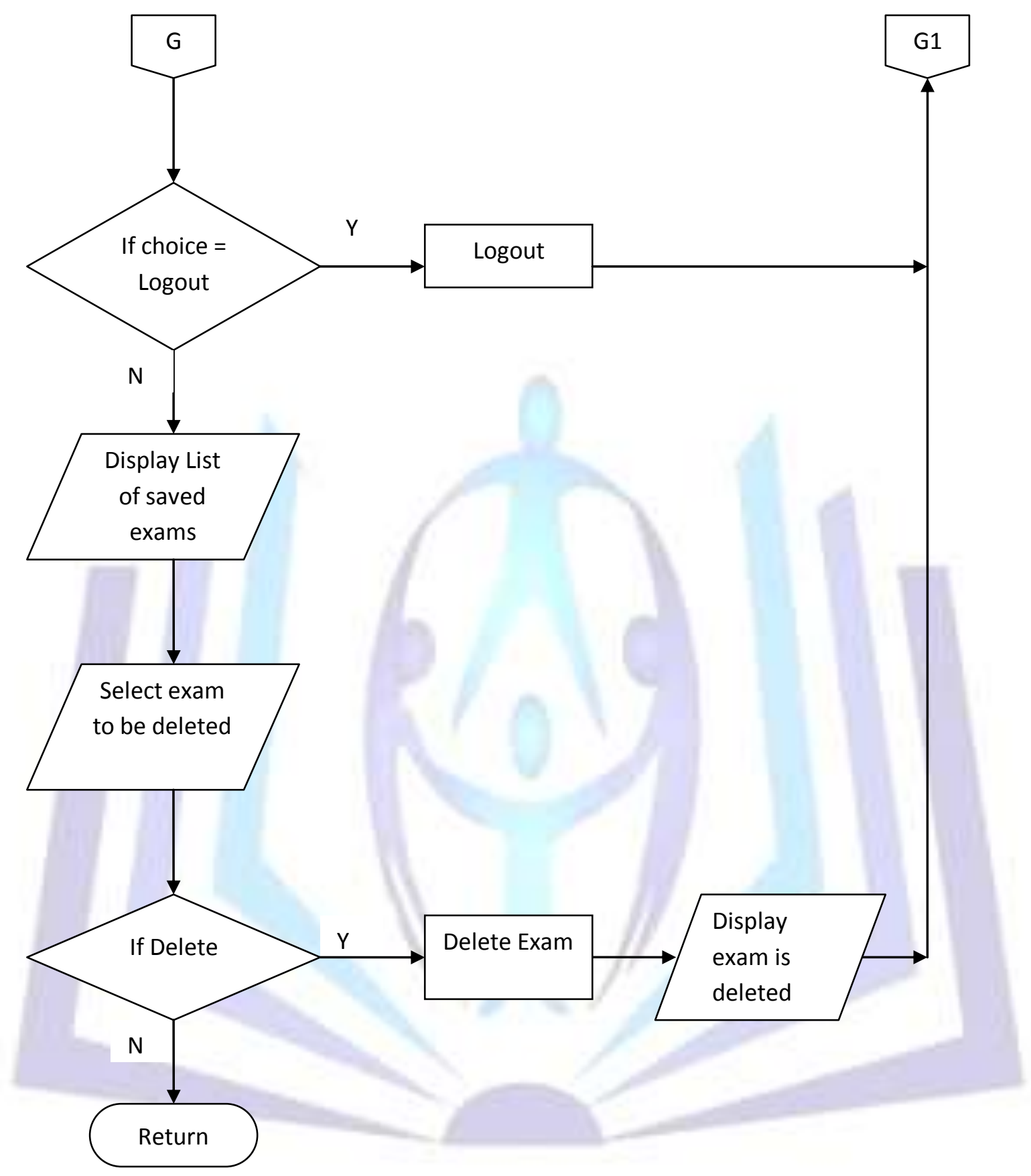

Figure 23. Delete Exam continued

Figures 22 and 23 show the sub links when the Delete Exam link is clicked. This option is available for instructors only. In this page, the instructor is enabled whether to delete an exam or cancel it. The user can also see a description about the Online Exam Maker and Checker if the About Online Exam Maker and Checker link is clicked and if he is done with the above actions, he may logout by clicking on the logout link. 


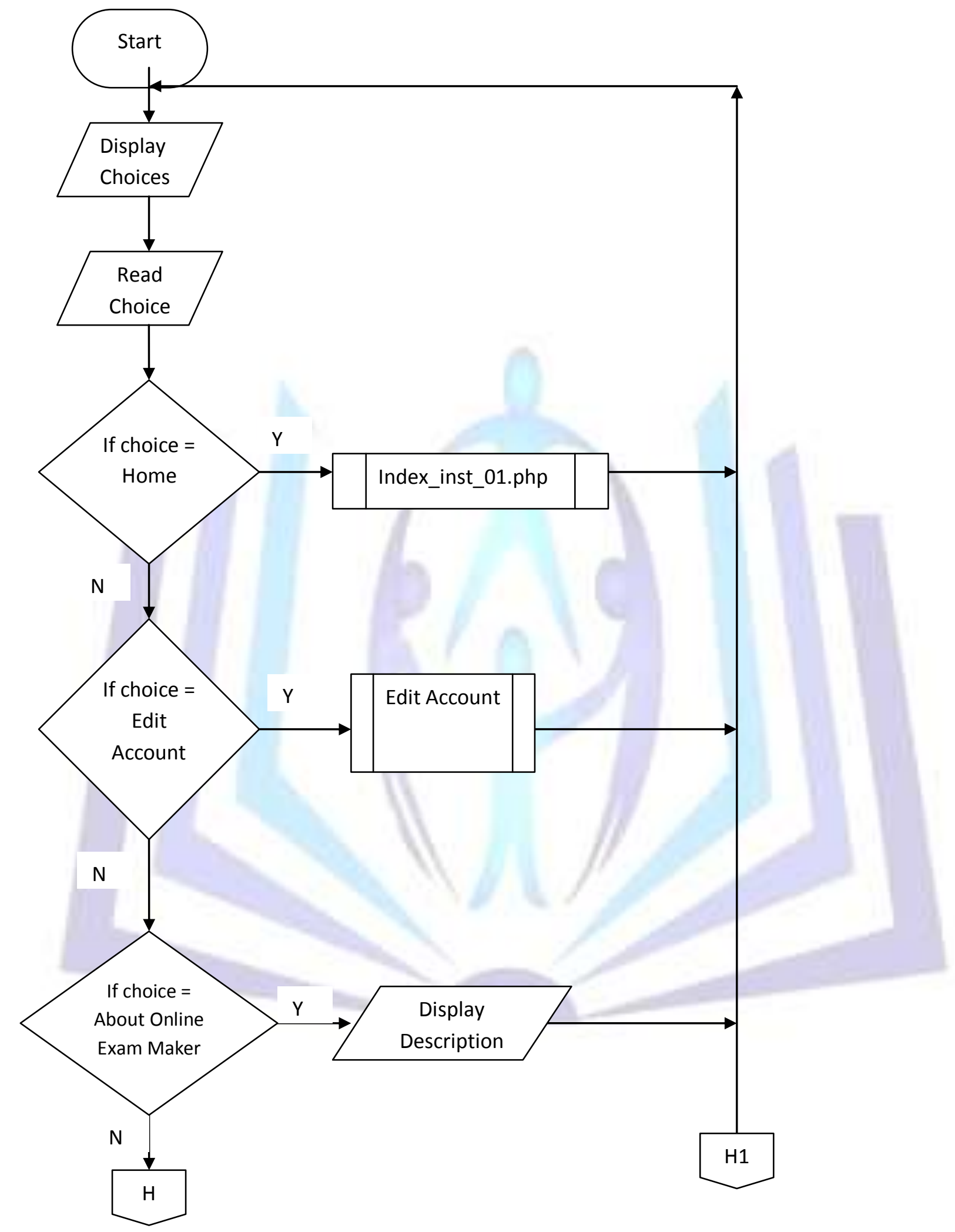

Figure 24. Class Home 


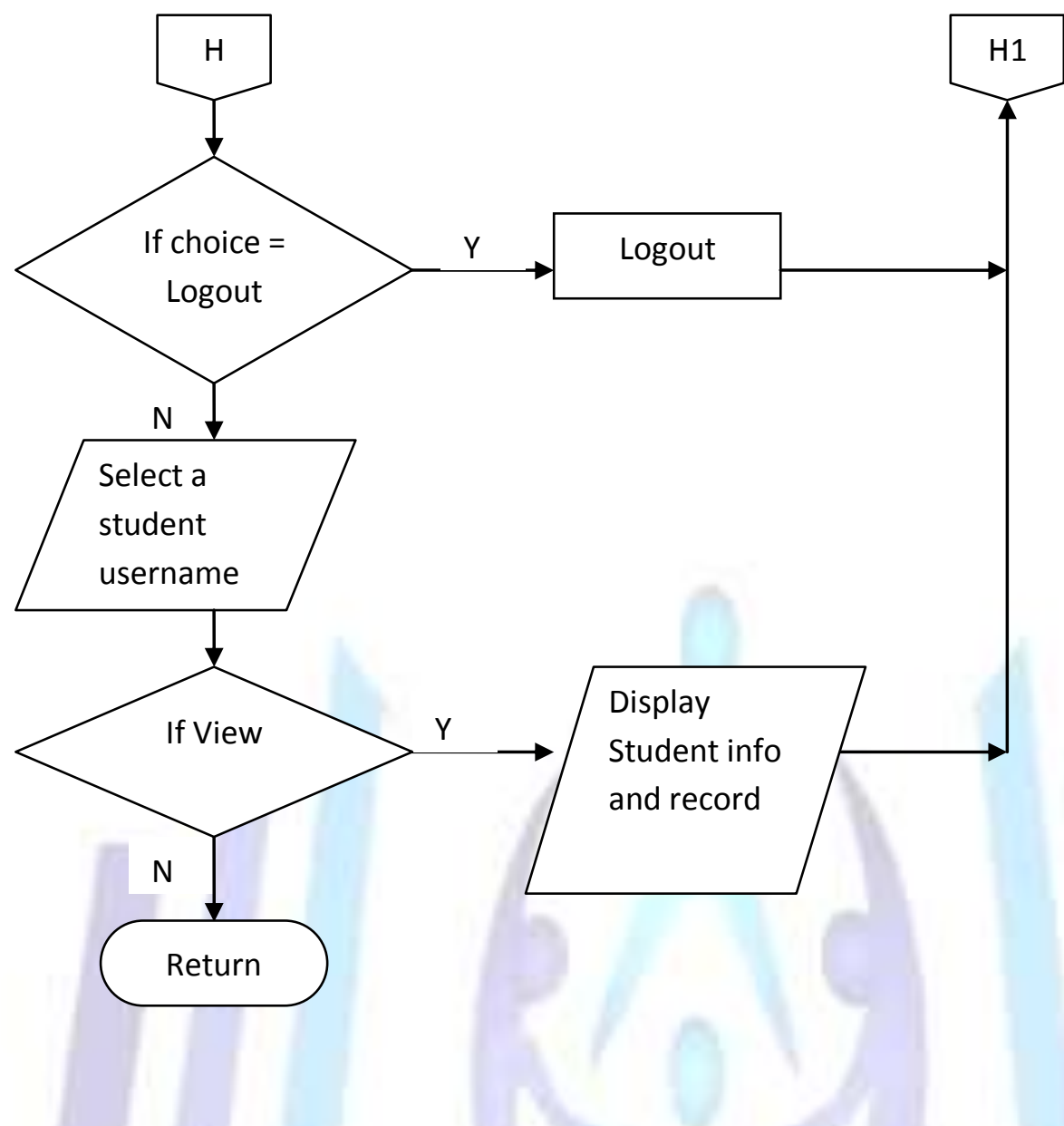

Figure 25. Class Home continued

Figures 24 and 25 show the sub links when the Class Home link is clicked. This option is available for instructors only. In this page, the instructor may select the name of the student and be able to view the selected student's record. The user can also see a description about the Online Exam Manager if the About Online Exam Manger link is clicked and if he is done with the above actions, he may logout by clicking on the logout link. 


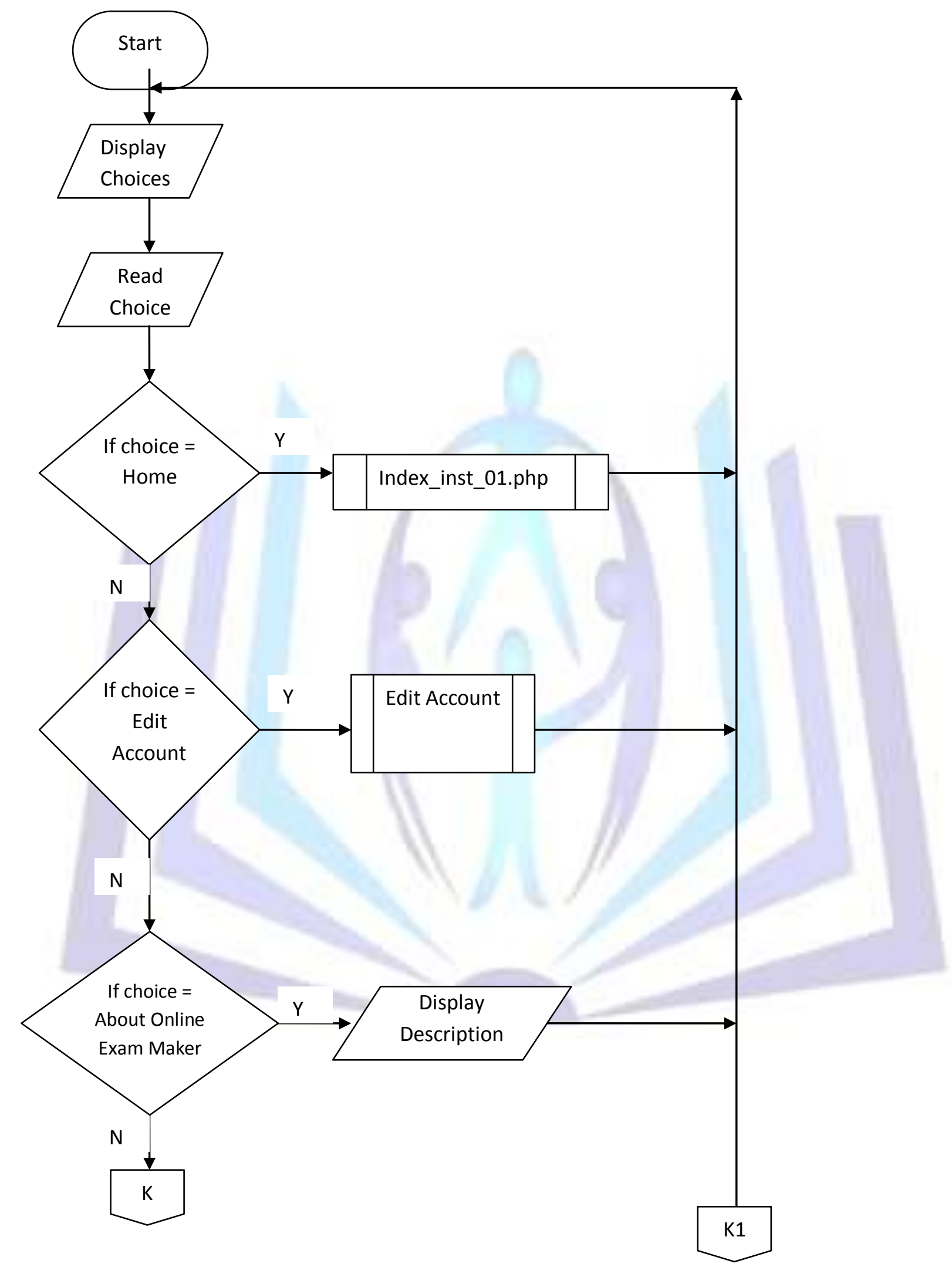

Figure 26. EClass 


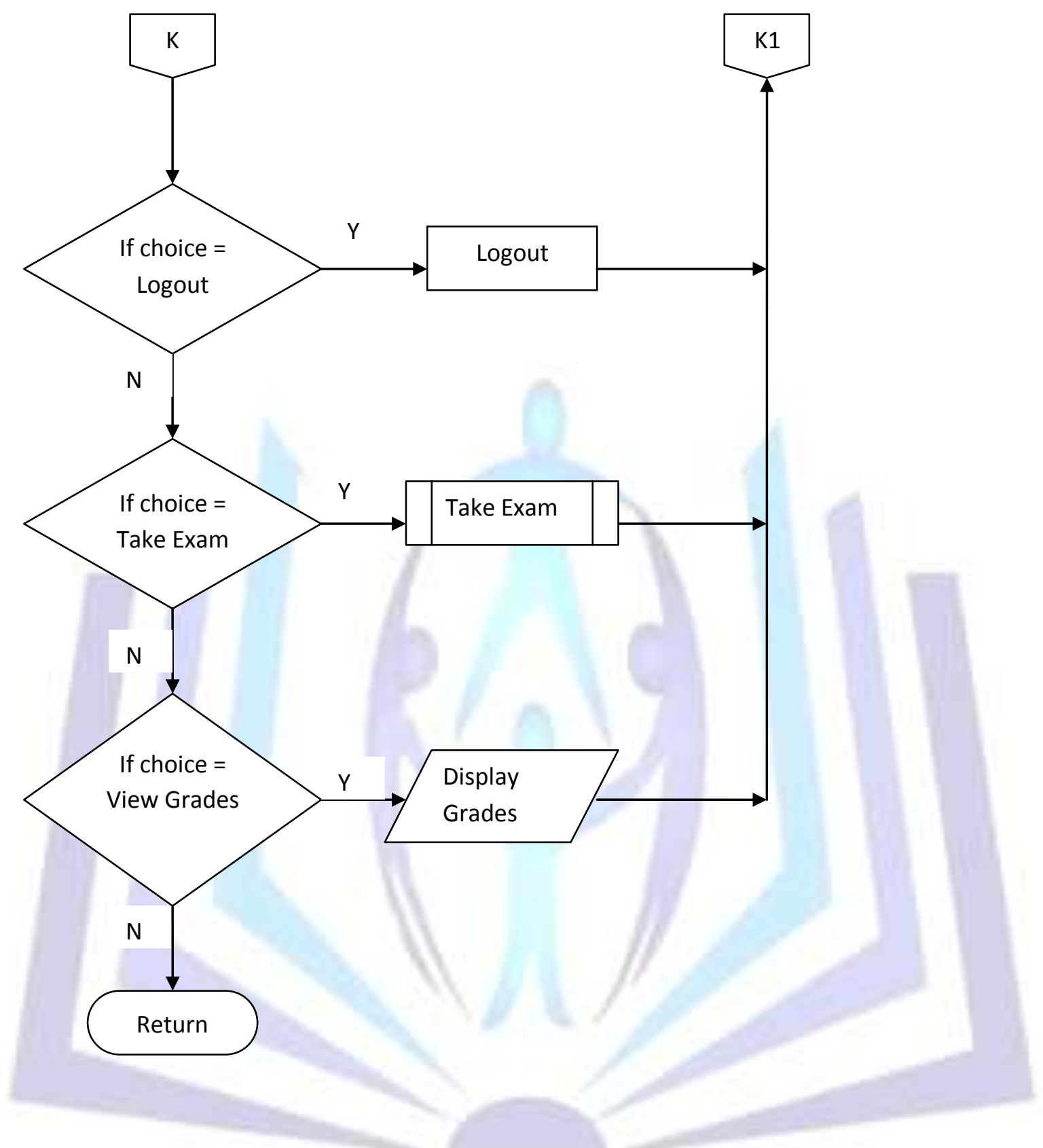

Figure 27. EClass continued

Figures 28 and 29 show the sub links when the EClass link is clicked. This option is available for students only. In this page, the student may view his Grade book and take activated exams in the particular class to which he is enrolled. The user can also see a description about the Online Exam Maker and Checker if the About Online Exam Maker and Checker link is clicked and if he is done with the above actions, he may logout by clicking on the logout link. 


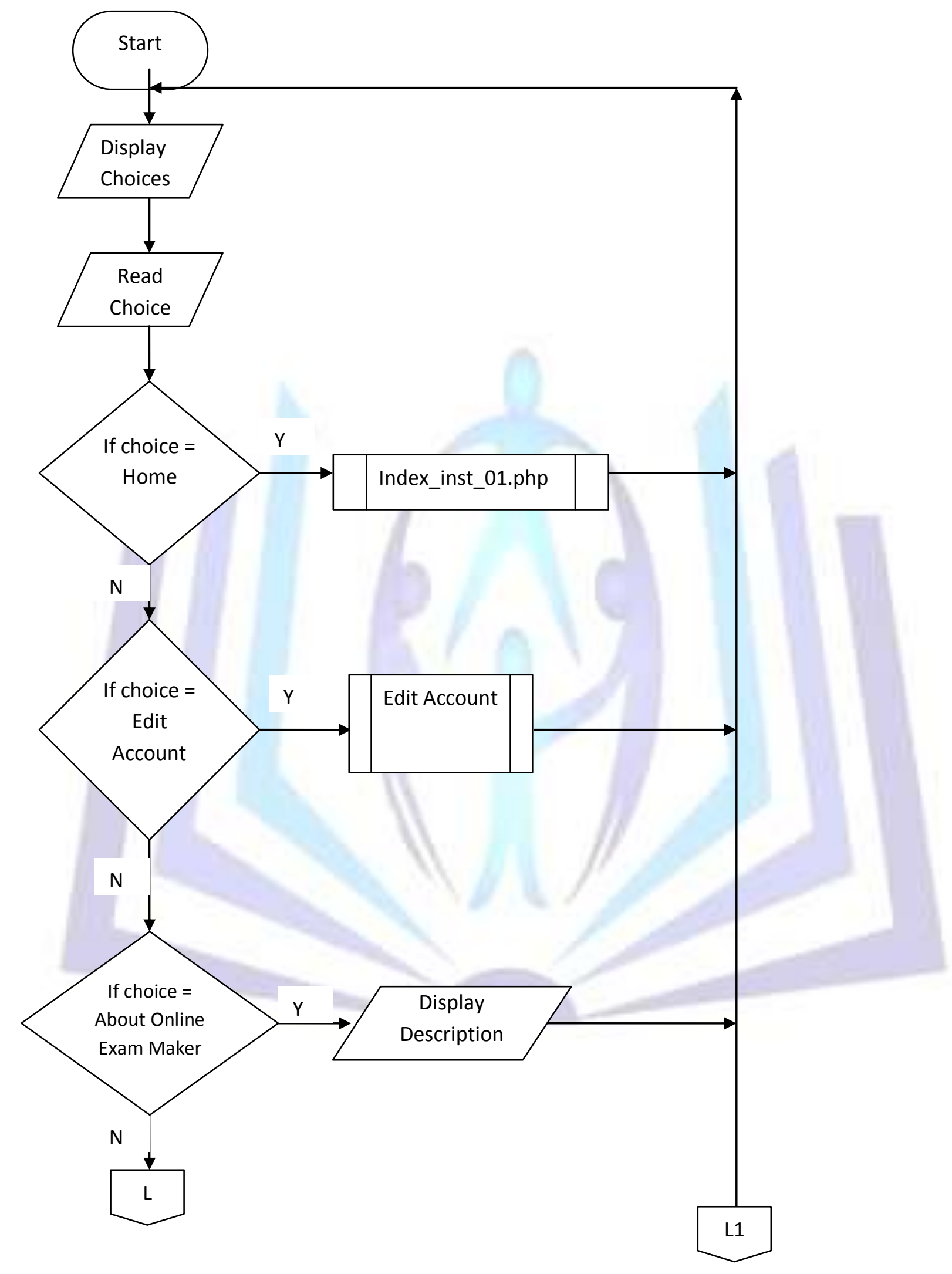

Figure 28. Take Exam 


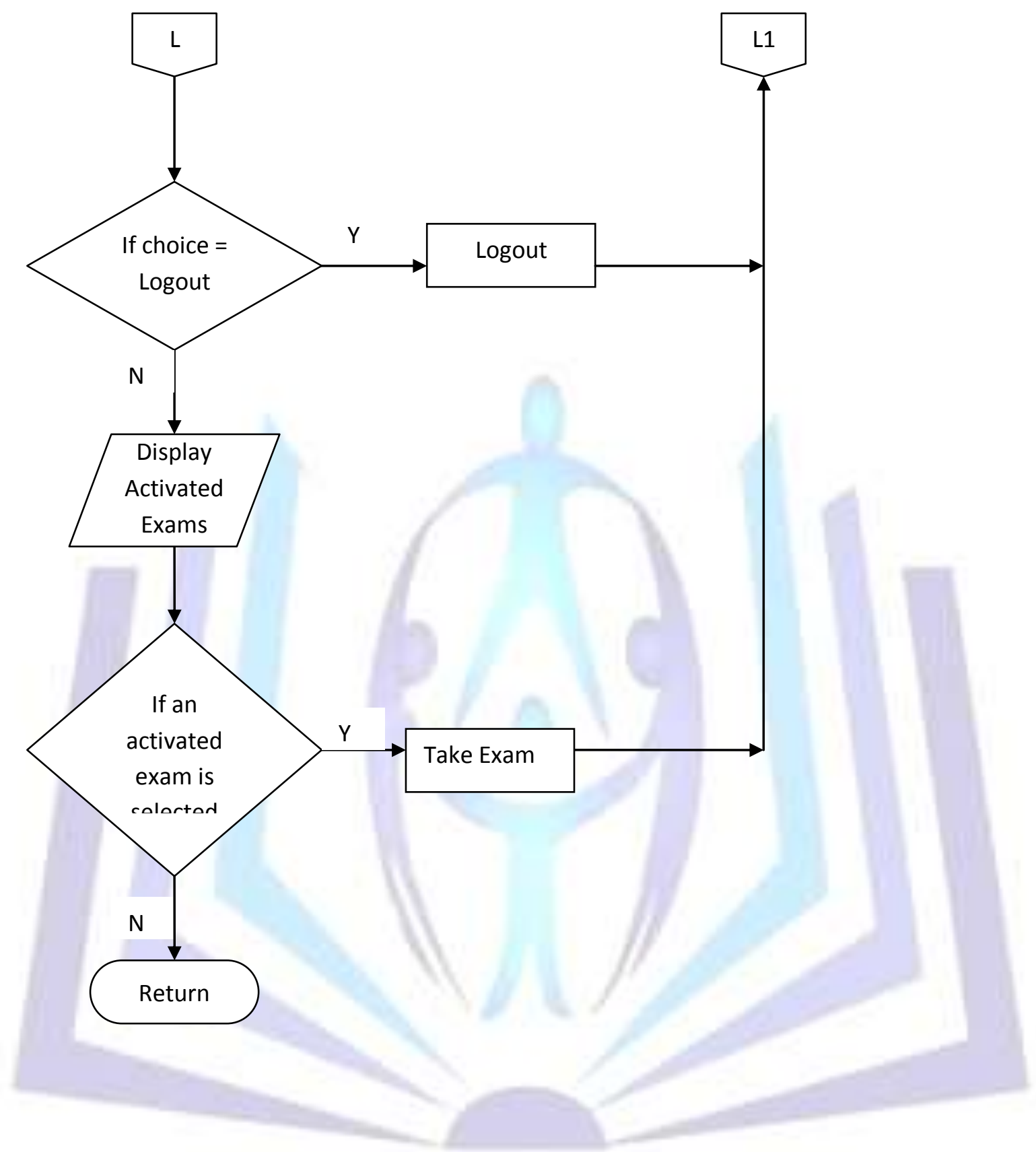

Figure 29. Take Exam continued

Figures 28 and 29 show the sub links when the Take Exam link is clicked. This option is available for students only. In this page, the student is enabled to take activated exams in the particular class to which he is enrolled. The user can also see a description about the Online Exam Maker and Checker if the About Online Exam Maker and Checker link is clicked and if he is done with the above actions, he may logout by clicking on the logout link. 


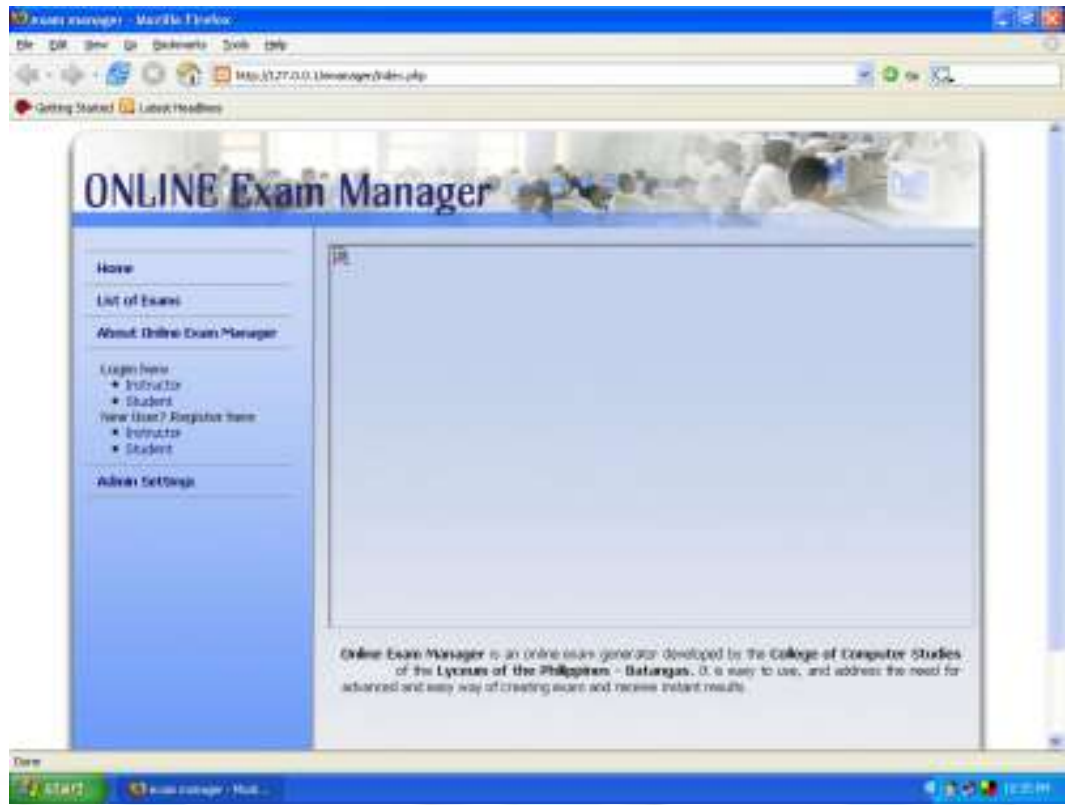

Figure 30. Index Page

This is the Index page which contains clickable links for the user such as Home, List of Exams, About the Online Exam Maker and Checker, Login, Register and Admin Settings.

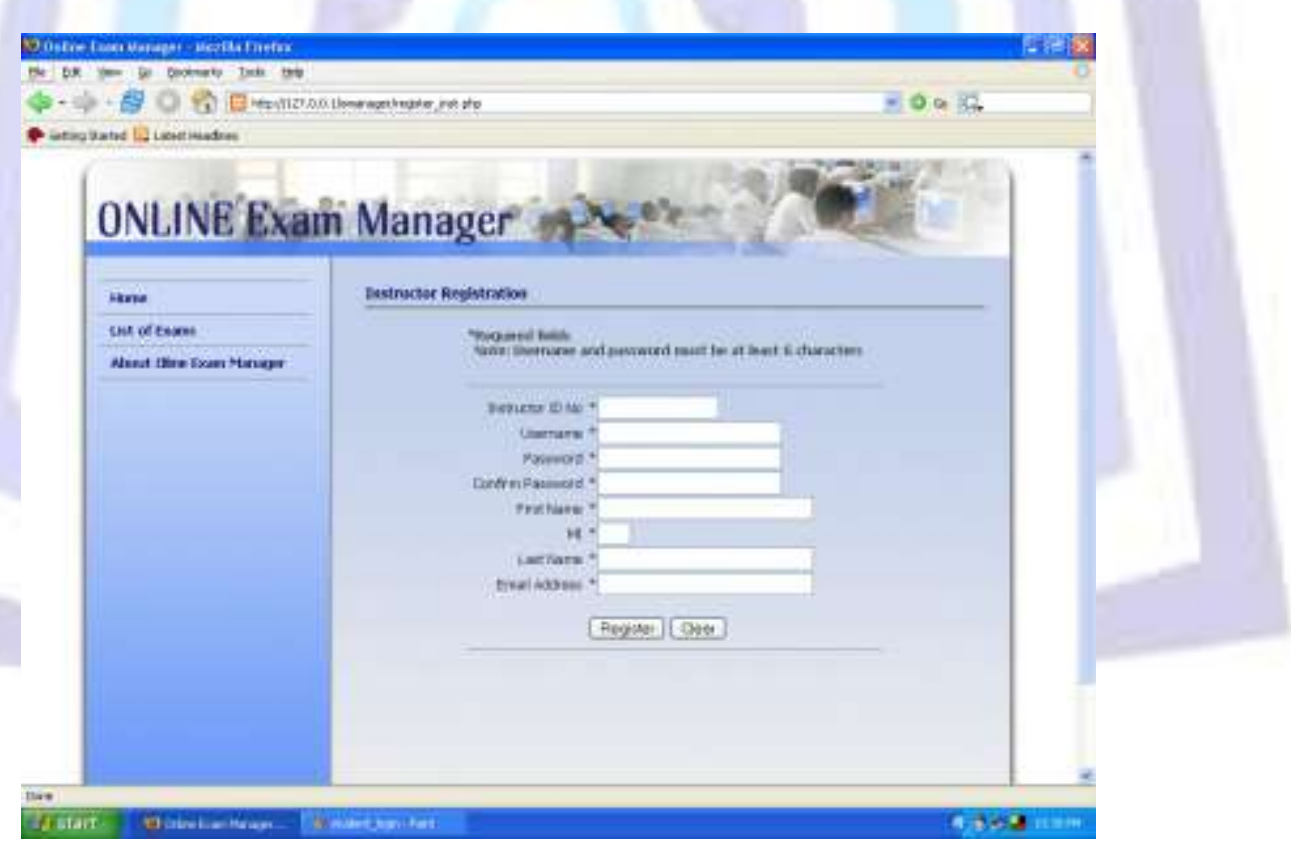

Figure 31. Instructor Registration Page

This is the Instructor's Registration page which enables instructors to enter the required information to gain access to the system. 


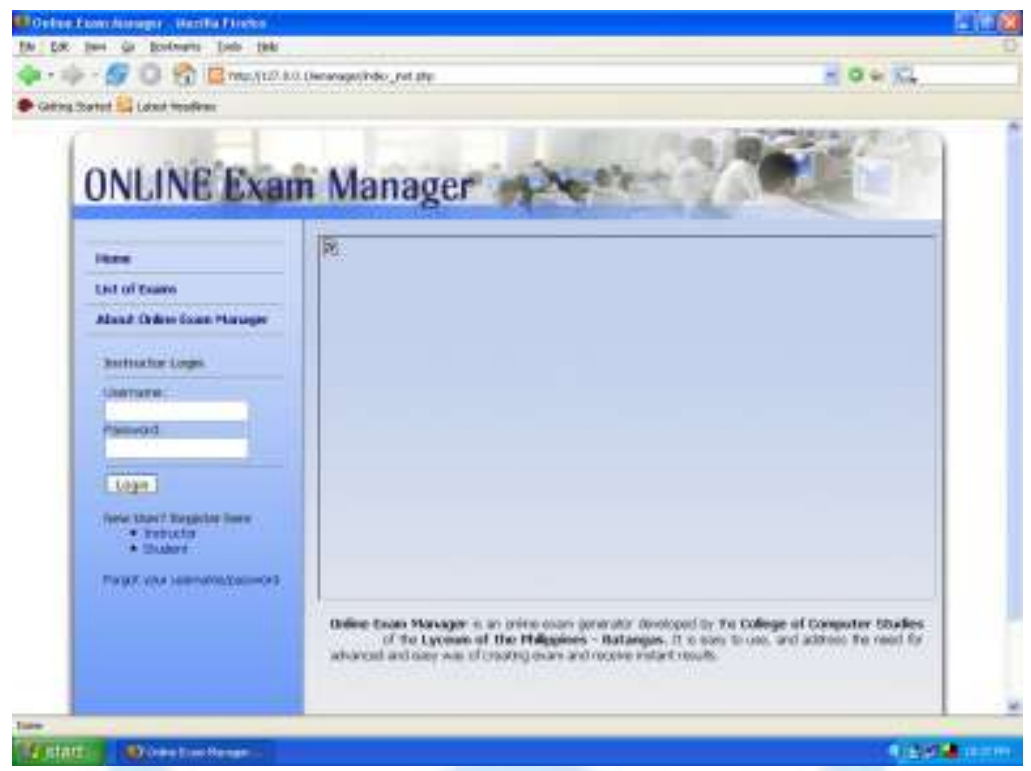

Figure 32. Instructor Login Page

This is the Instructor's Login page wherein the instructor, after completing the registration process, should enter the Username and Password to gain complete access of the system features.

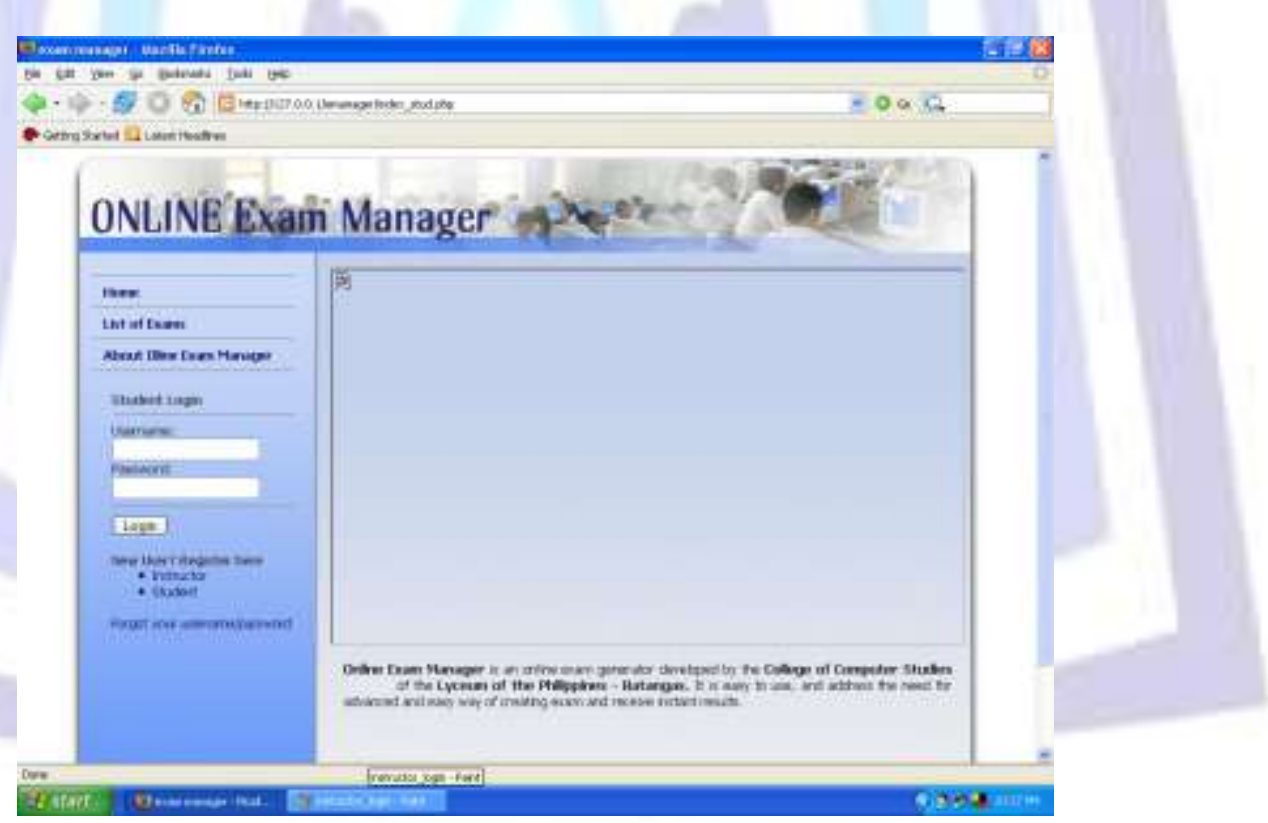

Figure 33. Student Login Page

This is the Student's Login page wherein the student, after completing the registration process, should enter the Username and Password to gain access of the system features. 


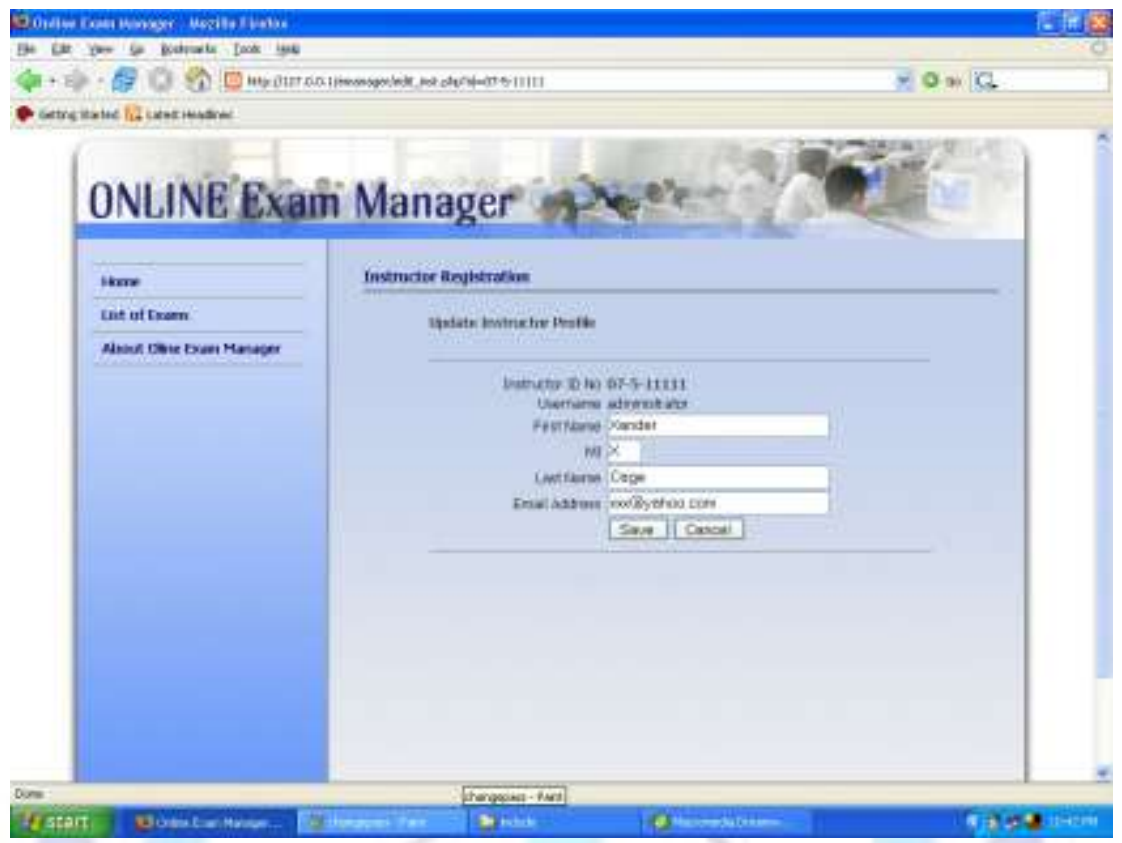

Figure 34. Edit Profile Page

This is the Edit Profile page which enables instructors and students to modify the information entered during the registration process.

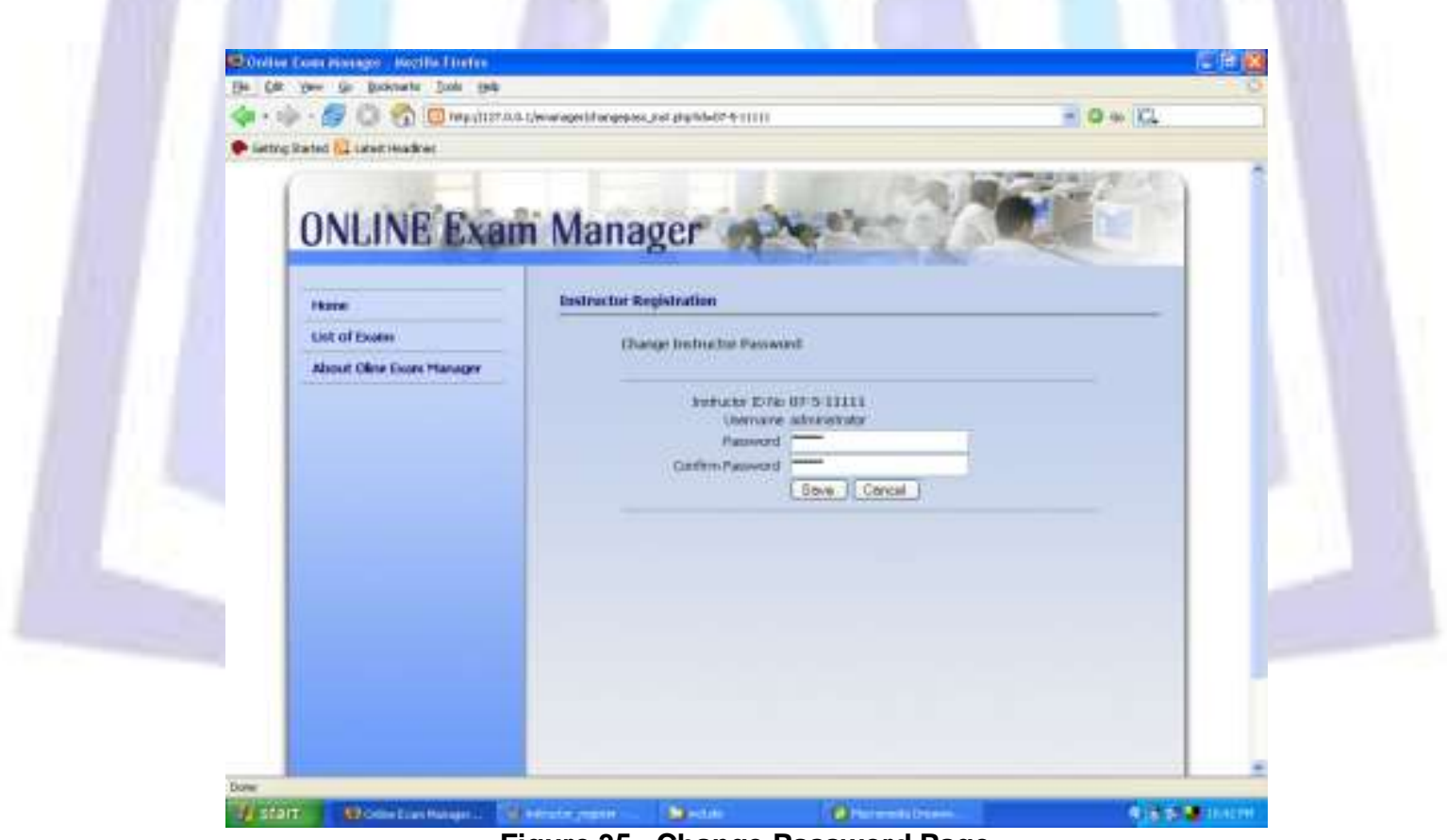

Figure 35. Change Password Page

This is the Change Password page which enables instructors and students to modify the password they prefer to use in logging in the system. 


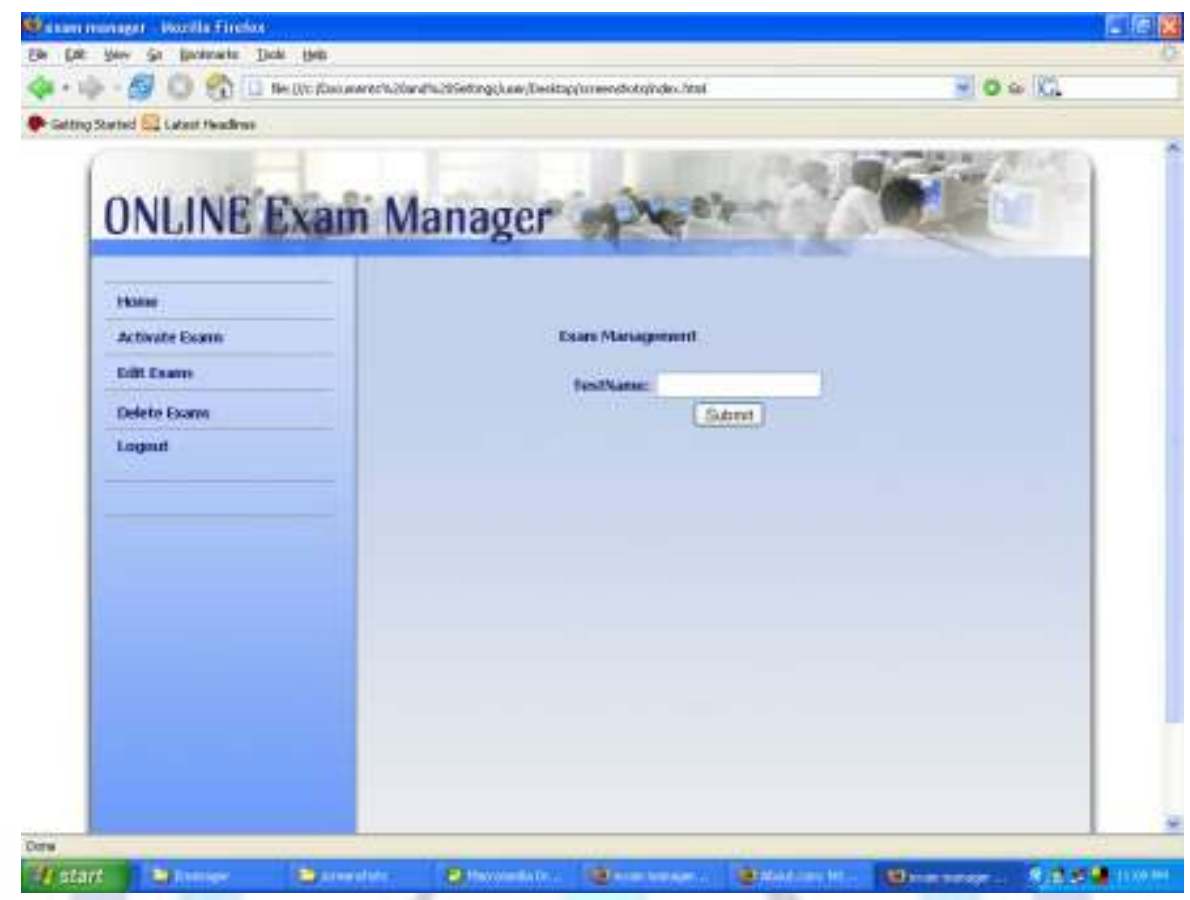

Figure 36. Create Exam Page

This is the Create Exam page which enables instructors to create online exams to be taken by the students enrolled in the class.

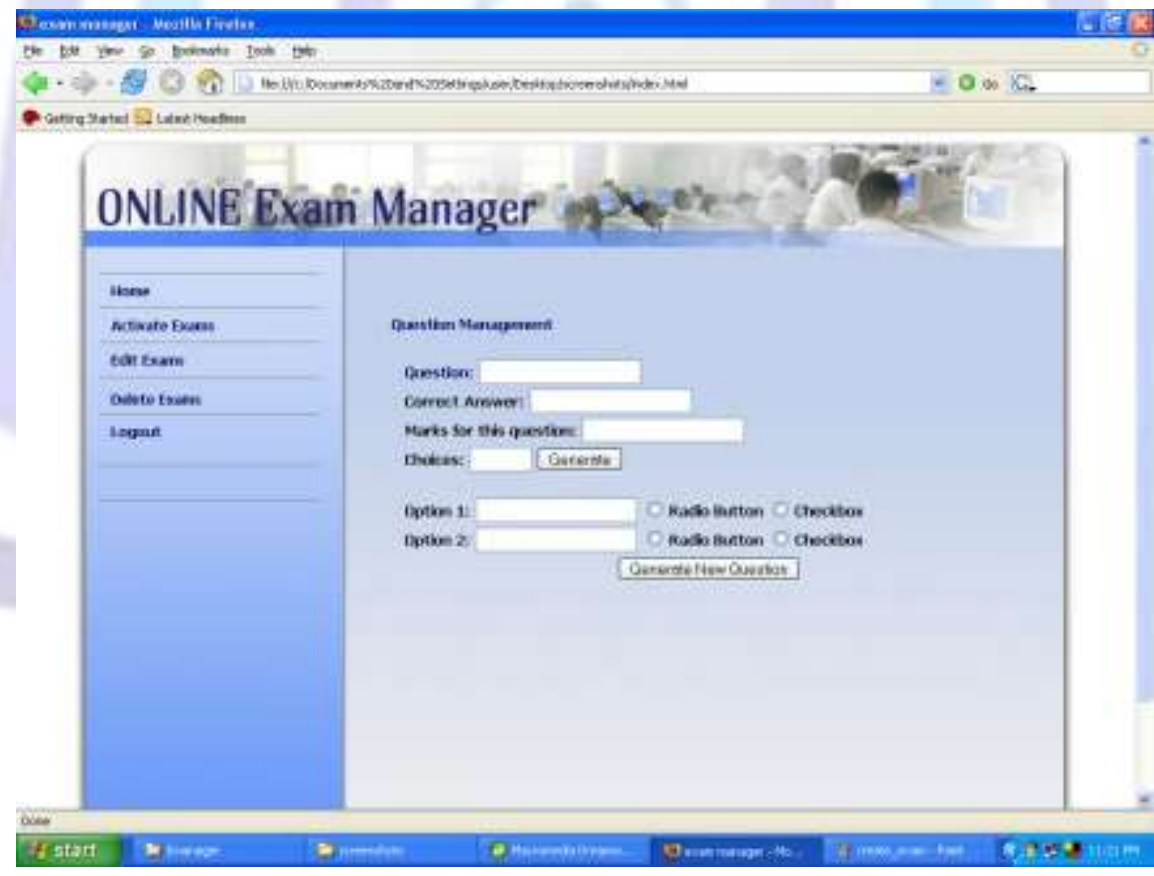

Figure 37. Question Management Page

This is the Question Management page which enables instructors to enter the questions to appear in the online exam. From here, the instructor is given the option as to what type of exam is to be created as well as the markings to be used. 


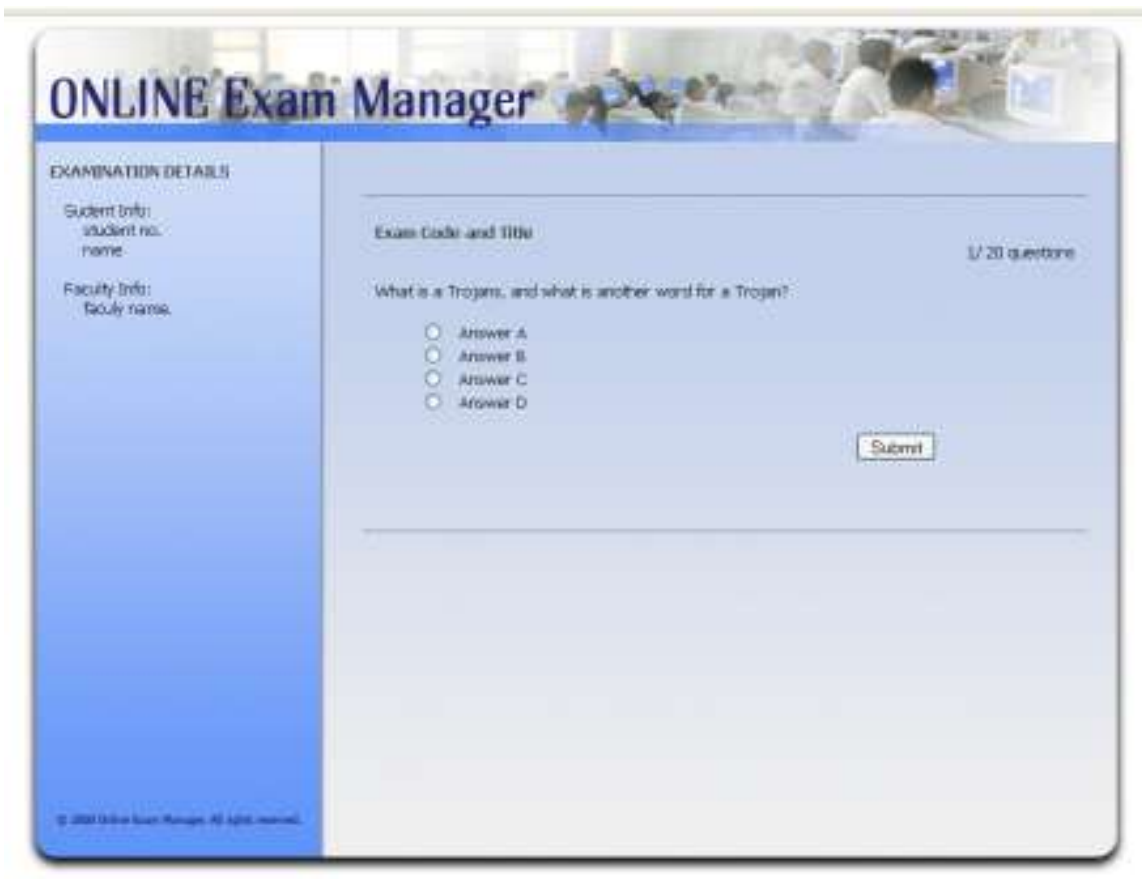

Figure 38. Exam Page

This is the Exam page which displays the questions created in the Question Management page. This shows the sample layout of the exam including the student's number and name, faculty member's name, exam code and title.

\section{DISCUSSIONS}

The main purpose of this study was to design and develop a computer - based testing software which can be accessed within the Integrated Virtual Learning Environment of the Lyceum of the Philippines University web page. One of its objectives was to provide an alternative for teachers to give and administer exams and also for the students to be able to experience and reap the benefits of online assessments.

Functions of the Online Exam Maker and Checker included the online creation of classes by assigned teachers, enrollment of students to these classes, and the creation of examinations for these students. The most important function was the checking of answers and generation of scores in real time; and for the teachers; a database which serves as storage of all examination results of each student. This helped lessen the use of paper and pencil method which in turn economized resources for both teachers and students.

Security and confidentiality were vital factors in the creation of examinations, actual assessments and the generation and storage of scores, thus a username and password were required for each account holder whether it be the administrator, teacher or student account.

\section{CONCLUSIONS}

Based on the findings of the study, the following conclusions were drawn within the limitation and scope defined in the study.

- The developed software served as an alternative tool for students in taking examinations in their respective classes.

- The developed software was a useful tool for the instructors in the preparation and checking of examinations as well as the maintenance of an online class record.

- The developed software was a tool equipped with security features useful in minimizing cheating during examinations among students.

- The developed software provided a useful tool in administering online exams rather than the traditional paperbased exams. 


\section{RECOMMENDATIONS}

After having evaluated the findings of the study, the following recommendations were hereby suggested:

- The Online Exam Maker and Checker should be used in administering exams in the different classes to help minimize cheating among students during such activity.

- $\quad$ Since the Online Exam Maker and Checker is linked to the IVLE of the Lyceum of the Philippines University web page, resources that the school is providing for the IVLE should be in compatibility with the requirements of the Online Exam Maker and Checker. The required resources are the acquisition and renewal of licensed operating systems and servers, and the purchase of servers for full implementation of the IVLE.

- Since the IVLE is monitored by a systems administrator, who is responsible in keeping the IVLE functioning properly at all times, this should also include the supervision and monitoring of instructor accounts in the Online Exam Maker and Checker.

- Future researchers and developers can add modules and additional features such as a time limit in the administration of exams, randomization of questions and incorporating different exam types in one exam set which were not included in the developed software.

- A follow up study to determine the usefulness and effectiveness of the developed software as compared to paper and pencil method is also recommended.

\section{REFERENCES}

[1] Alday, Roselie B. and Hernandez, Charnell. "My Lyceum Tech Learn - A Learning Management System for Lyceum of the Philippines - Batangas: An Instructional Aid for Teachers", 2008.

[2] Aojula, Harmesh, et. al. "Computer-based, online summative assessment in undergraduate pharmacy teaching: The Manchester experience", School of Pharmacy and Pharmaceutical Sciences, University of Manchester, Manchester M13 9PL, UK, and Distributed Learning Group, University of Manchester, Manchester M13 9PL, UK, (Received February 2006; revised 19 June 2006; accepted 27 June 2006)

[3] Baleros, Jerwin, et. al. "Expert System in Choosing a CAS Course in Batangas City", Lyceum of Batangas, March 2006.

[4] Billings, Karen, "Online Assessment: Perspectives Of Developers", School Executive, January/February 2004 issue

[5] Cordero, Ronald, et. al. "Electronic Class Record and Computerized Grading System in Lyceum of Batangas", Lyceum of Batangas, March 2007.

[6] Escalona, Judy, et. al. "Automated Entrance Examination Result of Lyceum of Batangas", Lyceum of Batangas, March 2007

[7] Ji-Hoon Lee, "Internet-Based Exam Generator System for Review of the Fundamental of Engineering Exam" Retrieved January 22, 2009 from http://eml.ou.edu/paper/hoime.htm

[8] Lucio Kunha Tinoco, "Online Evaluation in WWW-based courseware: The QUIZIT System" Retrieved February 2 , 2009 from http://scholar.lib.vt.edu/theses/available/etd-638192839711171

[9] C. Ricketts, S. J. Wilks, "Improving Student Performance Through Computer-based Assessment: insights from recent research", Assessment and Evaluation in Higher Education, Vol. 27, No. 5, 2002

[10] Salvatore Valenti, Information Technology for Assessing Student Learning, DIIGA - Universita' Politecnica delle Marche Ancona, Italy, Journal of Information Technology Education, Volume 2, 2003

[11] Salvatore Valenti, Alessandro Cucchiarelli, and Maurizio Panti, Computer Based Assessment Systems Evaluation via the ISO9126 Quality, Istituto di Informatica, Università di Ancona, Italy, Journal of Information Technology Education Volume 1 No. 3, 2002 


\section{Author's biography}

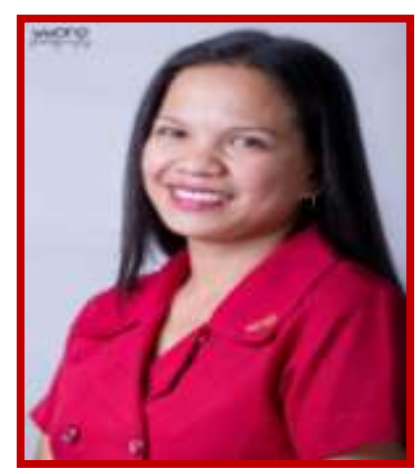

JANICE ECHALUCE VELASQUEZ is working as a college instructor at Lyceum of the Philippines University under the College of Computer Studies. For seventeen years, she has been handling professional subjects like computer applications, computer programming, systems analysis and design, software engineering, computer networking and thesis advising. She finished her BS in Information and Computer Science (BSICS) at Lyceum of the Philippines University (formerly Lyceum of Batangas) in 1996 and completed her Master of Science in Computer Science (MSCS) degree in 2010 from AMA Computer College in Makati City, Philippines. Her focused research area includes systems development, computer networking and mobile applications development. She is also a member of the Philippine Society of Information Technology Educators (PSITE) and Computer Science Teachers Association (CSTA).

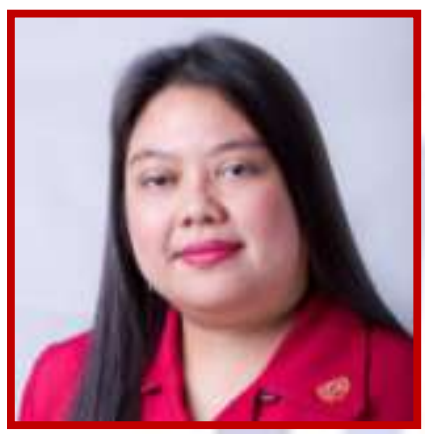

MARIA CRISTINA M. RAMOS is working as an assistant professor in Lyceum of the Philippines University - Batangas under the College of Computer Studies. She handles professional subjects like Artificial Intelligence, Database Systems, HumanComputer Interaction, Systems Analysis \& Design, Computer Programming and Capstone/Thesis advising, She finished BS in Computer Science at Western Philippine Colleges and completed MS in Computer Science at AMA Computer College in Makati City, Philippines. She is a member of (PELS) Philippine eLearning Society, (PSITE) Philippine Society of Information Technology Educators and (CSTA) Computer Science Teacher's Association. 